\title{
On the variability of the semidiurnal solar and lunar tides of the equatorial electrojet during sudden stratospheric warmings
}

\author{
Tarique A. Siddiqui ${ }^{1}$, Astrid Maute ${ }^{1}$, Nick Pedatella ${ }^{1}$, Yosuke Yamazaki ${ }^{2}$, Hermann Lühr ${ }^{2}$, and Claudia Stolle ${ }^{2,3}$ \\ ${ }^{1}$ High Altitude Observatory, National Center for Atmospheric Research, Boulder, CO, USA \\ ${ }^{2}$ GFZ German Research Centre for Geosciences, Potsdam, Germany \\ ${ }^{3}$ Faculty of Science, University of Potsdam, Potsdam, Germany
}

Correspondence: Tarique A. Siddiqui (tarique@ucar.edu)

Received: 5 July 2018 - Discussion started: 6 July 2018

Revised: 3 October 2018 - Accepted: 26 October 2018 - Published: 23 November 2018

\begin{abstract}
The variabilities of the semidiurnal solar and lunar tides of the equatorial electrojet (EEJ) are investigated during the 2003, 2006, 2009 and 2013 major sudden stratospheric warming (SSW) events in this study. For this purpose, ground-magnetometer recordings at the equatorial observatories in Huancayo and Fúquene are utilized. Results show a major enhancement in the amplitude of the EEJ semidiurnal lunar tide in each of the four warming events. The EEJ semidiurnal solar tidal amplitude shows an amplification prior to the onset of warmings, a reduction during the deceleration of the zonal mean zonal wind at $60^{\circ} \mathrm{N}$ and $10 \mathrm{hPa}$, and a second enhancement a few days after the peak reversal of the zonal mean zonal wind during all four SSWs. Results also reveal that the amplitude of the EEJ semidiurnal lunar tide becomes comparable or even greater than the amplitude of the EEJ semidiurnal solar tide during all these warming events. The present study also compares the EEJ semidiurnal solar and lunar tidal changes with the variability of the migrating semidiurnal solar (SW2) and lunar (M2) tides in neutral temperature and zonal wind obtained from numerical simulations at E-region heights. A better agreement between the enhancements of the EEJ semidiurnal lunar tide and the M2 tide is found in comparison with the enhancements of the EEJ semidiurnal solar tide and the SW2 tide in both the neutral temperature and zonal wind at the E-region altitudes.
\end{abstract}

\section{Introduction}

Sudden stratospheric warming (SSW) events are large-scale wintertime polar meteorological phenomena, which usually occur in the Northern Hemisphere. These events are marked by a deceleration of the climatological westerly zonal mean zonal winds in the polar stratosphere and a sudden increase in the polar stratospheric temperature by several tens of degrees (e.g. Andrews et al., 1987). SSWs result from the breaking of amplified planetary waves propagating up from the troposphere and their interaction with the stratospheric zonal mean flow (e.g. Matsuno, 1971). These amplified planetary waves deposit momentum in the easterly direction in the polar stratosphere that results in the deceleration of the zonal mean zonal wind and also induces a mean meridional circulation (e.g. Haynes et al., 1991), which leads to an enhanced downwelling in the polar region and an increase in the polar stratospheric temperature due to adiabatic heating. As a result of SSWs, the polar vortex is generally observed to either get displaced from the pole or split into two vortices (e.g. Charlton and Polvani, 2007). According to the definition from the World Meteorological Organization (WMO), SSWs can be classified into major and minor warming events based on the extent of deceleration of the zonal mean zonal wind at $60^{\circ} \mathrm{N}$ and $10 \mathrm{hPa}$ pressure level. SSWs that only involve a deceleration of the zonal mean zonal winds at these levels without a complete reversal are termed as minor warmings, and in cases where the zonal mean zonal winds reverse, they are termed as major warmings.

The SSW-induced effects are not only limited to the polar stratosphere but are rather observed across many different regions of the atmosphere (e.g. Pedatella et al., 2018a). 
The warming in the polar stratosphere is accompanied by a cooling in the equatorial stratosphere (e.g. Fritz and Soules, 1970). In the mesosphere, the SSWs lead to cooling at polar latitudes (e.g. Labitzke, 1972; Liu and Roble, 2002) and warming at the equatorial latitudes (e.g. Garcia, 1987; Chandran and Collins, 2014). In the Southern Hemisphere, the SSW-related effects lead to warming in the mesosphere through inter-hemispheric coupling mechanisms (e.g. Karlsson et al., 2009; Körnich and Becker, 2010). Coincident with the occurrence of SSWs, observations and modelling results have reported the lower thermospheric warming at middle and polar latitudes (e.g. Liu and Roble, 2002; Goncharenko and Zhang, 2008; Funke et al., 2010). In the ionosphere, evidence of the impact of SSWs at equatorial and low latitudes has been reported in the form of enhanced semidiurnal perturbations in vertical plasma drift velocities (e.g. Chau et al., 2009), total electron content (e.g. Goncharenko et al., 2010), electron densities (e.g. Lin et al., 2013) and the equatorial electrojet (e.g. Vineeth et al., 2009; Fejer et al., 2010; Yamazaki et al., 2012). These perturbations have mainly been attributed to the modulation of the atmospheric solar and lunar tides during SSWs (e.g. Chau et al., 2012; Pedatella and Liu, 2013).

Atmospheric tides are global-scale oscillations of the atmosphere with periods and sub-periods of the solar and lunar days (Lindzen and Chapman, 1969). The lower atmospheric solar tides are forced thermally through the periodic absorption of solar radiation by stratospheric ozone and tropospheric water vapour, while the atmospheric lunar tides are mainly gravitationally forced. The solar and lunar tides generated in the lower atmospheric regions propagate vertically upward and upon reaching the dynamo-region heights, they drive ionospheric currents (e.g. Baker et al., 1953). One such current flow as a result of this wind-driven dynamo is the equatorial electrojet (EEJ). It is a narrow ribbon of intense current flowing above the dip equator in the E-region of the ionosphere (e.g. Chapman, 1951). It is a daytime phenomenon and is confined to a latitudinal width of about $\pm 3^{\circ}$. The zonal polarization electric fields that drive the EEJ are generated by the ionospheric wind dynamo mechanism (e.g. Heelis, 2004), and the intense current in the EEJ is the result of the Cowling conductivity effect (Cowling, 1932) at the magnetic equator.

The variations in the EEJ due to solar and lunar tidal changes during SSWs have been a widely studied topic in recent years. However, the evidence of large changes in the EEJ during Northern Hemisphere winters due to the modulation of atmospheric lunar tides has been known since the work of Bartels and Johnston (1940). They noticed the occurrence of occasional "big-L days", usually during DecemberFebruary, when anomalously enhanced lunar tidal variations accompanied by counter electrojets (CEJ) were observed in the horizontal component of the magnetic field. Stening et al. (1996) suggested an association between the occurrence of CEJs in northern winters and the SSWs. In recent years, a renewed interest in this topic has been generated following the works of Chau et al. (2009) and Fejer et al. (2010). These studies identified a conspicuous semidiurnal signature, which temporally shifts on succeeding days, in the F-region vertical plasma drifts and in the EEJ, and linked these observations to the occurrence of an SSW. Fejer et al. (2010) suggested that this signature in the EEJ could be related to enhancements of the atmospheric lunar semidiurnal tide (M2). Since then, a number of studies have confirmed their findings using magnetic observations from satellite (e.g. Park et al., 2012) and ground-based observatories (e.g. Yamazaki et al., 2012; Yamazaki, 2013; Sathishkumar and Sridharan, 2013; Siddiqui et al., 2017; Yadav et al., 2017). Numerical and observational studies (e.g. Liu et al., 2010; Fuller-Rowell et al., 2010; Jin et al., 2012; Pedatella et al., 2014) also revealed the enhancement of the solar semidiurnal tide (SW2) at mesospheric and thermospheric altitudes during SSWs. These findings led to a number of mechanisms being proposed in recent years to explain the changes in the atmospheric semidiurnal tides during SSWs. The SW2 amplification during SSWs is attributed to the changes in the distribution of ozone (e.g. Goncharenko et al., 2012; Sridharan et al., 2012), changes in the tidal propagation conditions (e.g. Jin et al., 2012) and interaction with the enhanced planetary waves (e.g. Liu et al., 2010). The cause of the M2 amplification is proposed to be the shifting of the secondary atmospheric resonance peak towards the lunar semidiurnal period (e.g. Forbes and Zhang, 2012). The variabilities of the solar and lunar tides of the EEJ have been studied during the 2006 and the 2009 SSW events using magnetometers over the Indian sector by Sathishkumar and Sridharan (2013), and enhancements in both the solar and lunar semidiurnal tides of the EEJ were reported. Yamazaki (2014) has also estimated the relative importance of the solar and lunar current systems and found that the absolute changes in solar and lunar current systems are comparable during SSWs.

In this study, we use the data from the Huancayo and Fúquene magnetic observatories to examine the EEJ solar and lunar semidiurnal tidal enhancements during the 2003, 2006, 2009 and 2013 major SSW events. The main purpose of this paper is to investigate the temporal evolution of the semidiurnal solar and lunar tidal amplitude enhancement relative to the reversal of the zonal mean zonal wind at $60^{\circ} \mathrm{N}$ and $10 \mathrm{hPa}$. Model simulations of the $2009 \mathrm{SSW}$ event (e.g. Jin et al., 2012; Fang et al., 2012; Pedatella et al., 2014), in particular, have shown an enhancement in the amplitude of SW2 in the lower thermosphere prior to the onset of the SSW, followed by a reduction during the deceleration of the zonal mean zonal wind at $60^{\circ} \mathrm{N}$ and $10 \mathrm{hPa}$, and then another enhancement of SW2 after the peak reversal of the zonal mean zonal wind. We further investigate if the semidiurnal solar tide of the EEJ also shows a similar variability during SSWs as seen in the SW2 from the simulated neutral temperature and zonal wind. The EEJ variability is known to be dominated by the variability of the E-region zonal wind at the equatorial and low latitudes (e.g. Yamazaki et al., 2014). The 


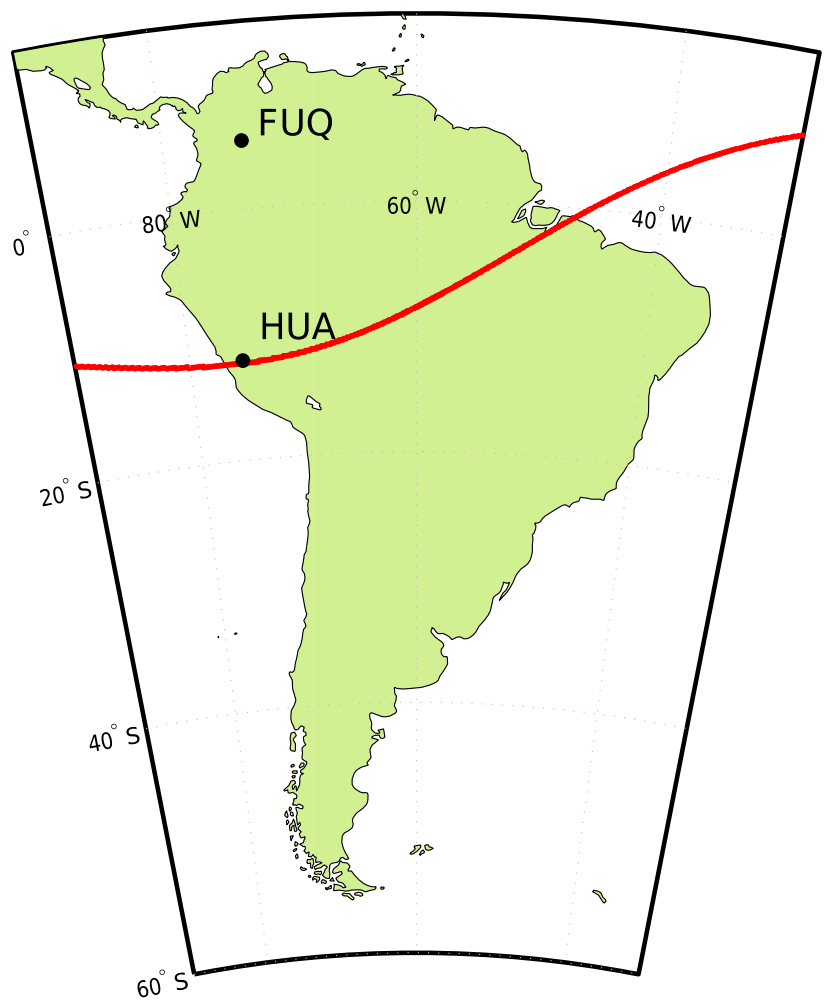

Figure 1. The locations of the Huancayo (HUA) and Fúquene (FUQ) observatories are marked with black dots in this figure. The red line denotes the dip equator.

outline of the paper is as follows. Section 2 describes the data sets used in this study. In Sect. 3, the analysis methods used for determining the EEJ solar and lunar tidal amplitudes are described. Section 4 presents the observations, followed by discussion in Sect. 5 and the conclusions in Sect. 6.

\section{Data set}

The hourly mean values of the horizontal component of the geomagnetic field at Huancayo $\left(-12.05^{\circ} \mathrm{N}, 284.67^{\circ} \mathrm{E}\right.$; magnetic latitude: $\left.-0.6^{\circ}\right)$ and Fúquene $\left(5.47^{\circ} \mathrm{N}, 286.26^{\circ} \mathrm{E}\right.$; magnetic latitude: $18.12^{\circ}$ ) are downloaded from the website of the World Data Centre (WDC) for Geomagnetism, Edinburgh. The night-time baseline values of the magnetic field are estimated by making use of the five monthly international quiet days (IQDs), and these dates are available from the website of the German Research Centre for Geosciences (GFZ), Potsdam. Daily solar flux $\left(F_{10.7}\right)$ values (Tapping, 2013) have been downloaded from the GSFC/SPDF OMNIWeb interface at http://omniweb.gsfc.nasa.gov (last access: 20 November 2018).

The SSW events are identified by following the definition of an SSW from the World Meteorological Organization (WMO). For this purpose, daily mean values of the North
Pole temperature at $10 \mathrm{hPa}$ and the zonal wind at $60^{\circ} \mathrm{N}$ and $10 \mathrm{hPa}$ are obtained from the National Centers for Environmental Prediction/National Center of Atmospheric Research (NCEP/NCAR) reanalysis datasets (Kalnay et al., 1996).

\section{Methods of analysis}

\subsection{Estimating the EEJ strength from ground-magnetometer recordings}

The strength of the EEJ is estimated by using the horizontal component of the ground-magnetometer recordings at Huancayo (HUA) and Fúquene (FUQ). The locations of the two observatories are marked in Fig. 1. The difference of the horizontal magnetic fields between an observatory located under the EEJ and another located outside of the EEJ can be used to estimate the strength of the EEJ (Rastogi and Klobuchar, 1990). The steps for this calculation have been described in detail for the HUA and FUQ observatories in Siddiqui et al. (2015b) and are only briefly summarized here in the following paragraph.

For both the observatories, the mean of the night-time values between 23:30 and 02:30 LT are calculated for the five monthly IQDs. The mean of the quiet night-time values are used to approximate the magnetic effects of the Earth's main field. Thereafter, these values are subtracted from the recorded magnetic data at both observatories and the daily variation with respect to the night-time baseline values are computed. The large-scale fields due to the magnetospheric ring current and the solar quiet $(\mathrm{Sq})$ current systems are removed when the difference between the horizontal magnetic fields of the two observatories is calculated (e.g. Manoj et al., 2006). On computing this difference, the hourly values of the EEJ strength are obtained. The EEJ values also show a strong dependence on the solar flux levels (e.g. Alken and Maus, 2007). To account for this dependence, the estimated EEJ strength has been normalized to a solar flux level of $150 \mathrm{sfu}$ (solar flux units) using the method described in Park et al. (2012).

\subsection{Estimating the solar and lunar tidal variations of the EEJ}

The dominant tidal components of the EEJ are the solar $(S)$ diurnal (24 solar hours) and semidiurnal (12 solar hours) variations. In addition, the EEJ also contains lunar $(L)$ tidal variations, which are mainly the result of the atmospheric lunar semidiurnal (e.g. M2, 12.42 solar hours) tidal component. The amplitude of $L$ in the EEJ is typically 1 order of magnitude less than the amplitude of $S$, but occasionally, it can become comparable to that of $S$ on certain big-L days (Bartels and Johnston, 1940), which are usually observed during the Northern Hemisphere winters. Recent studies have suggested that these days with enhanced lunar tidal effects are 
related to the occurrence of SSW events (e.g. Fejer et al., 2010; Siddiqui et al., 2015a).

In this study, the $S$ and $L$ variations of the EEJ are determined by using the methods described in Malin and Chapman (1970). Although the main focus of their study was the determination of the lunar daily variations in geophysical quantities using the Chapman-Miller method, they also described the method for determining the solar daily variations in geophysical quantities. The lunar and solar daily variations of the EEJ are mathematically expressed as follows.

The components of the $L$ variations are represented by the Chapman's phase law and can be expressed as

$L_{n}=l_{n} \sin \left(\frac{2 \pi}{24} n t-\frac{2 \pi}{24} 2 v+\lambda_{n}\right)$,

where $l_{n}$ denotes the amplitude of the $n$th component of the $L$ variations, $t$ denotes the solar local time in hours, $v$ denotes the lunar age in hours and $\lambda_{n}$ is the phase angle of the $n$th component.

The components of the $S$ variations can be expressed as

$S_{n}=s_{n} \sin \left(\frac{2 \pi}{24} n t+\sigma_{n}\right)$,

where $s_{n}$ and $\sigma_{n}$ denote the amplitude and phase of the $n$th harmonic component, respectively.

The $L$ and $S$ variations are simultaneously estimated by determining their four respective Fourier coefficients through a least-squares fitting of the normalized EEJ values by using the following expressions:

$L=\sum_{n=1}^{4} l_{n} \sin \left(\frac{2 \pi}{24} n t-\frac{2 \pi}{24} 2 \nu+\lambda_{n}\right)$,

$S=\sum_{n=0}^{4} s_{n} \sin \left(\frac{2 \pi}{24} n t+\sigma_{n}\right)$.

The $L$ variations of the EEJ are essentially semidiurnal because of the dominance of the $L_{2}$ term, and the $L$ variations are modified by other harmonics in such a way that they are smaller during the night than during the day (Malin and Chapman, 1970). It is important to keep note of this point, because the EEJ signals are absent during the night-time. Conte et al. (2017) showed that a window of length greater than 15 days is sufficient to resolve the solar and lunar semidiurnal tides in mesosphere-lower-thermosphere (MLT) winds in a similar least-squares fitting approach. Chau et al. (2015) found that when synthetic radar data were used to estimate the solar and lunar semidiurnal tides using a least-squares method with a 15-day moving window, the results yielded some artefacts. They found that a 21-day moving window was a good compromise, as it allowed the reduction of the artefacts and also the separation of the solar and lunar semidiurnal tides. In order to determine the amplitude and phase of the solar and lunar tidal components, we have used a 21-day moving window to perform the least-squares fitting in this study. While fitting the tidal components within each of the windows, we derive the amplitudes and phases of the different tidal components, which are then assigned to their corresponding central day.

\section{Observations and results}

In this section, we examine the day-to-day variabilities of the EEJ, the polar stratospheric conditions, and the semidiurnal solar $\left(S_{2}\right)$ and lunar $\left(L_{2}\right)$ tidal variations during the 20022003, 2005-2006, 2008-2009 and 2012-2013 major SSWs.

\subsection{2-2003 SSW event}

Figure 2a presents the normalized daily EEJ values, which have been scaled to $150 \mathrm{sfu}$, between 1 December 2002 and 1 March 2003. The days of new and full moon are represented by black and white circles, respectively. Figure $2 b$ shows the $L_{2}$ (blue line) and $S_{2}$ (red line) tidal amplitudes. Figure $2 \mathrm{c}$ shows the zonal mean zonal wind $(U)$ at $60^{\circ} \mathrm{N}$ and $10 \mathrm{hPa}$ (red line) pressure level and the North Pole temperature $(T)$ also at the $10 \mathrm{hPa}$ (black line) pressure level. Figure $2 \mathrm{e}$ presents the $F_{10.7}$ levels during this time interval. The onset of this SSW event begins during the final week of December, and the characteristic increase in the temperature at the North Pole and the reversal of the zonal mean zonal wind is seen later in January. During 28-31 December, the EEJ (Fig. 2a) weakens in the morning hours and counter electrojets are observed in the afternoon hours. Coinciding with the occurrence of the new moon, which occurs on 2 January, the semidiurnal perturbation pattern in the EEJ during SSWs increasingly shifts in local time on succeeding days. The amplification of the $L_{2}$ and the $S_{2}$ amplitudes (Fig. 2b) happens during this period, with the lunar tidal amplification clearly being the more dominant of the two. The $L_{2}$ amplitude increases by up to a factor of 2 compared to pre-SSW levels, while the $S_{2}$ amplitude shows only minor enhancement during this time interval. In Fig. 2b, the dotted lines represent the $1 \sigma$ uncertainty levels. The uncertainty levels of the leastsquares estimators are obtained by the methods described in Montgomery et al. (2012), and the uncertainty levels of the tidal amplitudes and phases are estimated by the methods described in Taylor (1997).

The amplitude of $L_{2}$ reaches a peak value of $27 \mathrm{nT}$ on 5 January, and the $S_{2}$ amplitude also reaches a peak value of $24 \mathrm{nT}$ on the same day. After this enhancement the $S_{2}$ amplitude starts to decrease, and on 21 January it reaches a minimum value of $15 \mathrm{nT}$. A second weaker perturbation pattern in the EEJ starts after the day of the full moon on 18 January. The uncertainty levels in the amplitudes of $L_{2}$ and $S_{2}$ are around $1.4 \mathrm{nT}$. The zonal mean zonal wind reaches a greater level of reversal during this period, but a similar enhancement in the $L_{2}$ amplitude is not observed. A second enhancement in the $S_{2}$ amplitude is seen to start after the minima on 


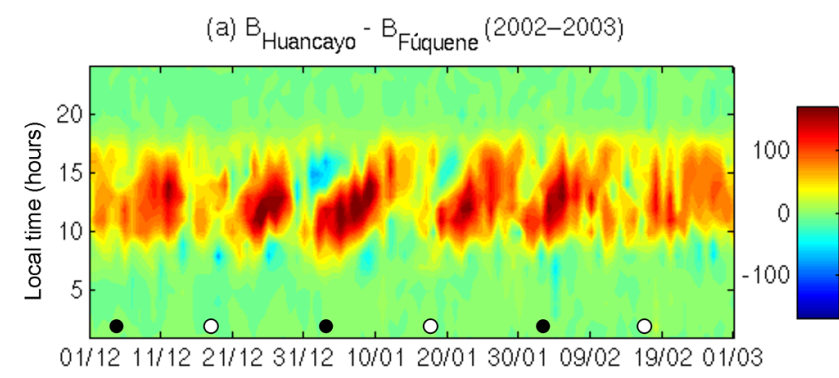

(b) Tidal amplitudes from Huancayo recordings during 2002-2003 SSW event
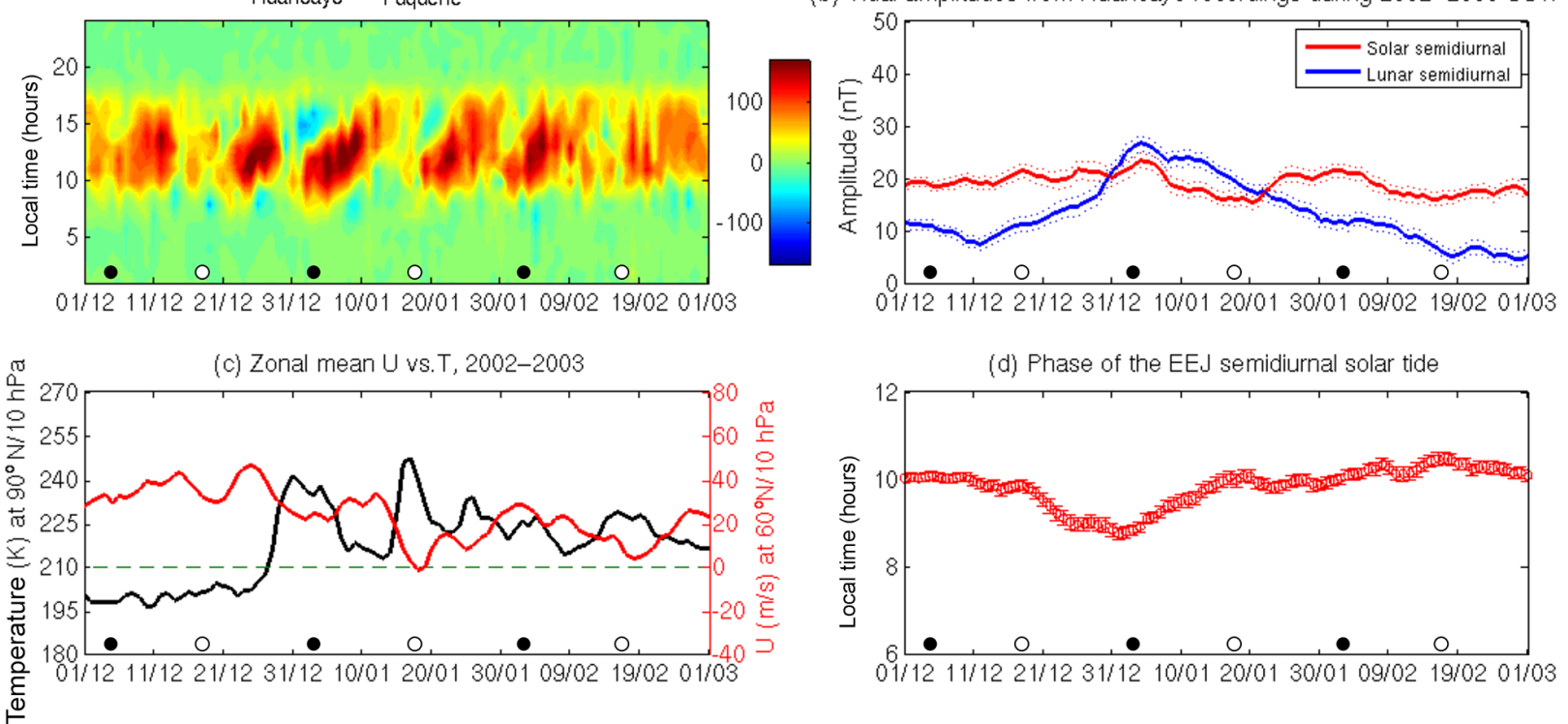

(d) Phase of the EEJ semidiurnal solar tide

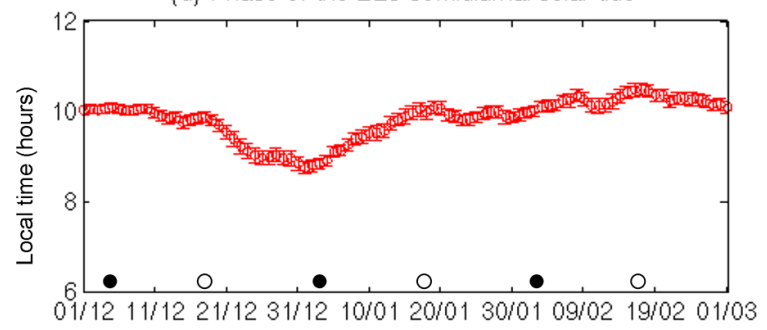

(e) Daily solar flux values, 2002-2003

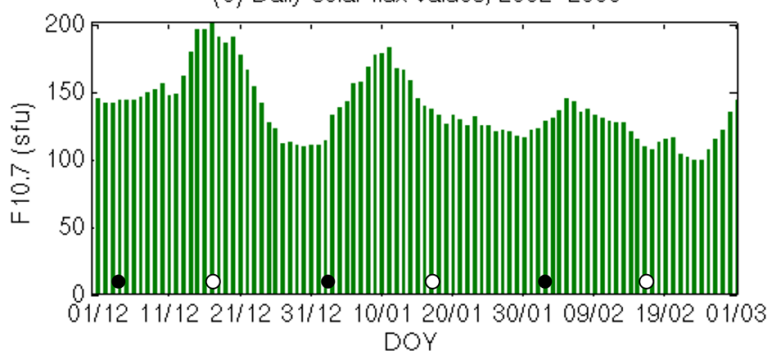

(f) Phase of the EEJ semidiurnal lunar tide

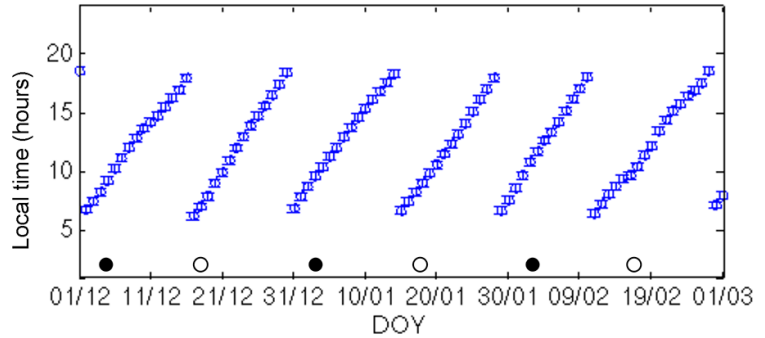

Figure 2. (a) the day-to-day variations of the EEJ obtained from Huancayo and Fúquene observatories between 1 December 2002 and 1 March 2003 are presented in this plot. The white and black dots at the bottom represent the days of full moon and new moon, respectively. (b) the amplitude of the semidiurnal solar (red) and lunar (blue) tides of the EEJ during the same period. The dotted lines represent the $1 \sigma$ uncertainty levels. (c) daily time series of the zonal mean zonal wind $(U)$ at $60^{\circ} \mathrm{N}$ and $10 \mathrm{hPa}$ (red), and the North Pole temperature at $10 \mathrm{hPa}$ (black) during the same period. The dashed green line is marked to identify the day of reversal of the zonal mean zonal wind. (d) the phase of the semidiurnal tide of the EEJ. (e) daily solar flux values during this time interval. (f) the phase of the semidiurnal lunar tide of the EEJ.

21 January, and it reaches a peak value of $22 \mathrm{nT}$ on 2 February. The $L_{2}$ amplitude, in the meantime, declines and reaches its pre-SSW levels. Figure $2 \mathrm{~d}$ and $\mathrm{f}$ present the phase variation of the $S_{2}$ and $L_{2}$, respectively. The phase of $S_{2}$ remains stable at around $10 \mathrm{~h}$ (LT) in the pre- and post-SSW periods. It starts to perturb slightly during the onset of the SSW moving to earlier times and reaches a minimum of $8.8 \mathrm{~h}(\mathrm{LT})$ on 1 January. Thereafter, it increases gradually and reaches the pre-SSW levels. The error bars in these figures denote the $1 \sigma$ uncertainty level. The phase of $L_{2}$, on the other hand, shows the expected progressive shift between 06:00 and 17:00 $\mathrm{h}$ of LT and no major perturbations in the $L_{2}$ phase are observed due to the $2003 \mathrm{SSW}$ event. The uncertainty levels in the phase of $L_{2}$ and $S_{2}$ are determined to be around $0.4 \mathrm{~h}$.

At the crossover points of the $L_{2}$ and $S_{2}$ phases, stronger EEJs are expected due to the constructive interference between the $L_{2}$ and $S_{2}$ tidal components. Equivalently, $S_{2}$ and $L_{2}$ wave troughs overlap typically around 15:00-16:00 LT on days shortly after the new and full moon. Zhou et al. (2018) found high occurrence rates of CEJ during that time span around the December solstice.

\section{$4.2 \quad 2005-2006$ SSW event}

From Fig. 3c, it is observed that the onset of the 20052006 SSW starts in the first week of January, and this event has multiple episodes of warming, with the North Pole temperature peaking on 4, 11 and 23 January. In Fig. 3a, on 10 13 January, the EEJ weakens, and counter-electrojet events are recorded after $10 \mathrm{~h}(\mathrm{LT})$. Coinciding with the occurrence of the full moon, the shifting semidiurnal perturbation pattern in the EEJ starts to evolve from 14 January, and the EEJ shows enhanced morning and weakened afternoon amplitudes. The reversal of the zonal mean zonal wind at $60^{\circ} \mathrm{N}$ and $10 \mathrm{hPa}$ is first witnessed on 22 January, and the peak wind reversal occurs on 26 January. The EEJ again weakens on 26-28 January prior to the appearance of a second perturbation pattern, which coincides with the occurrence of 

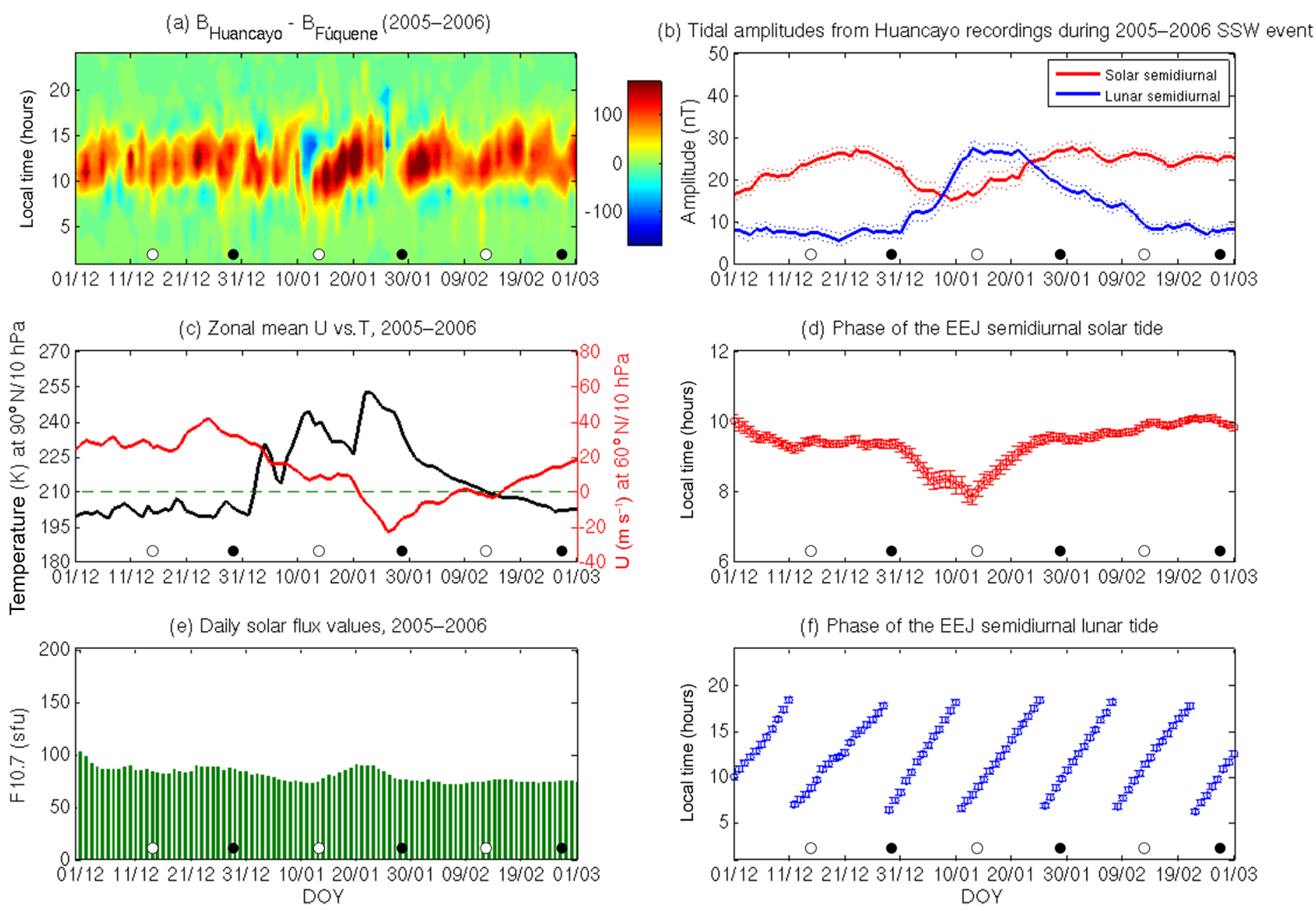

Figure 3. Same as Fig. 2, except between 1 December 2005 and 1 March 2006.

the new moon. The solar flux levels, shown in Fig. 3e, remain below 100 sfu during the 2006 SSW event.

In Fig. 3b, the amplitude of the $S_{2}$ (red line) and $L_{2}$ (blue line) tidal variations are presented. The dotted lines again represent the $1 \sigma$ uncertainty levels. The $L_{2}$ amplitude shows a sharp increase from $7 \mathrm{nT}$ on December 31 to $28 \mathrm{nT}$ on January 13 , during the onset of the SSW. It is approximately maintained at these levels until 22 January, before a sharp decline to pre-SSW levels is seen in February. The $S_{2}$ amplitude, on the other hand, is enhanced just before the onset of the SSW with the peak amplitude of $27 \mathrm{nT}$ being recorded on 25 December. Thereafter, it shows a decline following the start of the SSW and decreases to $15 \mathrm{nT}$ on 10 January. The $S_{2}$ amplitude is then again seen to enhance towards the end of January. The uncertainty levels for $S_{2}$ and $L_{2}$ amplitudes during the $2006 \mathrm{SSW}$ event lie around $1.6 \mathrm{nT}$.

In Fig. 3d, the phase of $S_{2}$ is presented. Like the case of the 2003 SSW event, the phase remains fairly constant between 9 and $10 \mathrm{~h}$ (LT) before the onset of the SSW event. It then decreases to $7.8 \mathrm{~h}$ (LT) during the SSW before returning to pre-SSW levels. In Fig. 3f, the phase of $L_{2}$ shows its characteristic propagation in solar local time. The uncertainty levels for the phase of $L_{2}$ and $S_{2}$ are found to be around $0.4 \mathrm{~h}$.

\section{$4.3 \quad 2008-2009$ SSW event}

The onset of the 2009 SSW can be observed to start in the second week of January in Fig. 4c. The North Pole temperature does not show major fluctuations during this period but a sudden decrease in the zonal mean zonal wind is seen to begin on 11 January. The enhancement in the North Pole temperature first starts on 19 January and then reaches a peak on 23 January. The zonal mean zonal wind, meanwhile, continues to decelerate and shows a reversal on 24 January followed by a minimum on 29 January. From Fig. 4a, it is observed that during the onset of the 2009 SSW event the EEJ amplitudes first weaken on 18-25 January, and after the occurrence of the new moon on 26 January, the progressing semidiurnal perturbation pattern in the EEJ is again visible. The 2009 SSW event was recorded during the minimum phase of the solar cycle, and the solar flux levels (Fig. 4e) were extremely low.

In Fig. $4 \mathrm{~b}$, the amplitude of the $L_{2}$ (blue line) starts increasing with the onset of the SSW and reaches a peak amplitude of $31 \mathrm{nT}$ on 29 January. The $L_{2}$ amplitude then starts to decline when the zonal mean zonal wind starts to recover and approximately reaches the pre-SSW levels. The tidal char- 


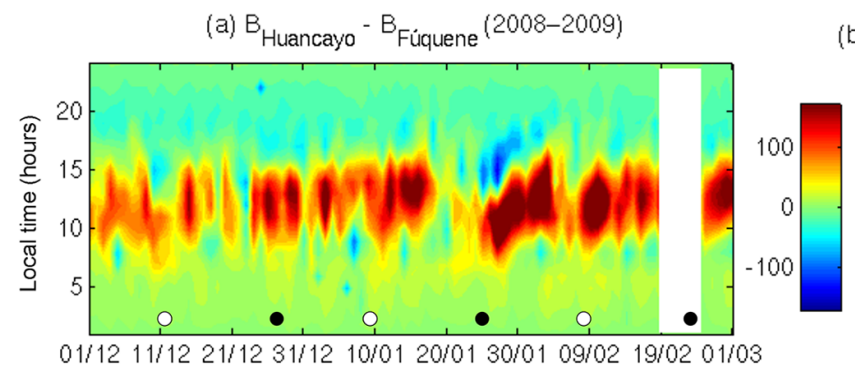

(b) Tidal amplitudes from Huancayo recordings during 2008-2009 SSW event
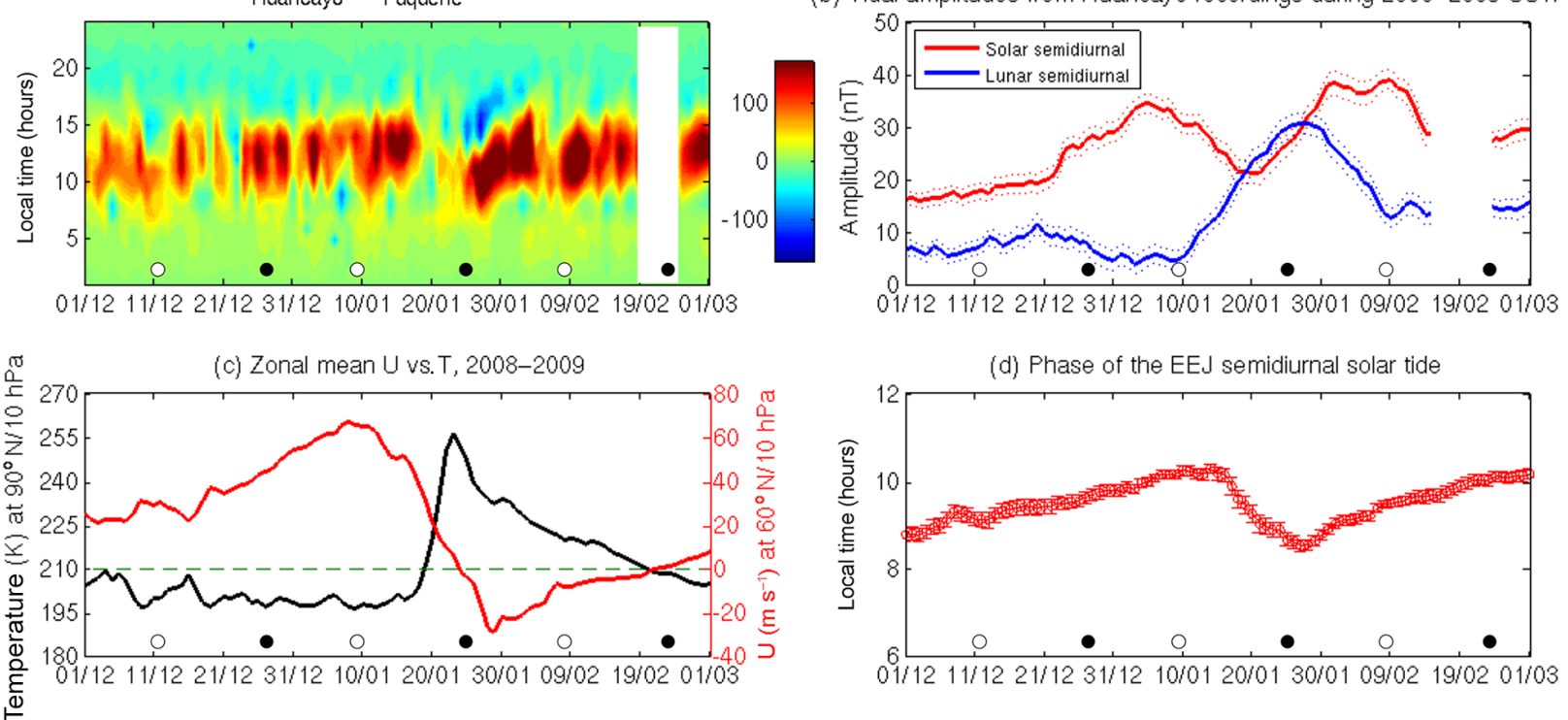

(d) Phase of the EEJ semidiurnal solar tide

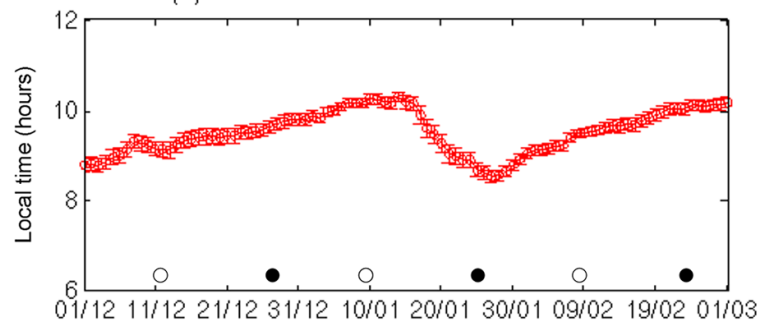

(e) Daily solar flux values, $2008-2009$

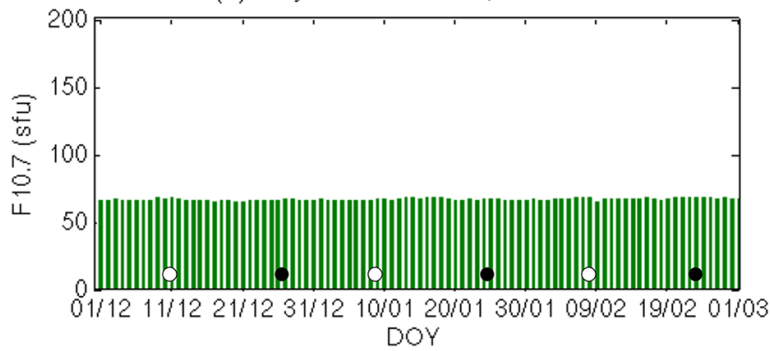

(f) Phase of the EEJ semidiurnal lunar tide

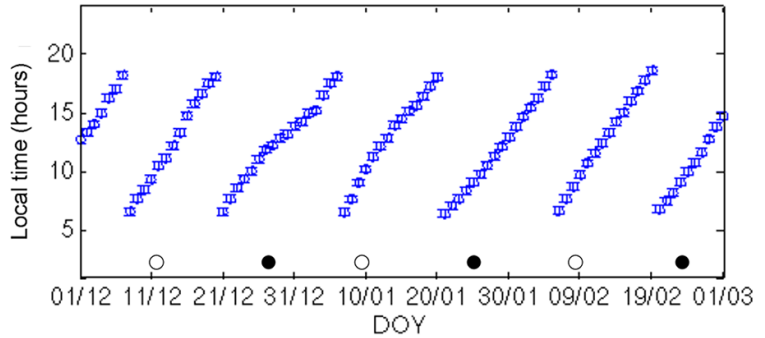

Figure 4. Same as Fig. 2, except between 1 December 2008 and 1 March 2009. The missing period of data is marked in white colour.

acteristics of the $S_{2}$ (red line) amplitudes are similar to the ones seen during the 2003 and 2006 SSW events. An earlier enhancement is observed at the onset of the SSW followed by a decline during the main phase of the SSW, and then another enhancement is observed following the peak zonal mean zonal wind reversal. In the 2009 SSW event, the first enhancement of $S_{2}$ is observed on 5 January, with a peak amplitude of $36 \mathrm{nT}$, and once the SSW moves into its main phase, the $S_{2}$ amplitude declines to a minimum of 21 nT on 20 January. Following the peak wind reversal, the $S_{2}$ amplitude enhances to $40 \mathrm{nT}$ in the first week of February. The uncertainty levels for $S_{2}$ and $L_{2}$ amplitudes during the 2009 SSW event are found to be around $1.6 \mathrm{nT}$.

The phase of $S_{2}$, as seen in Fig. 4d, shows a gradual increase in the month of December and peaks during the onset of the SSW. In the main phase of the SSW, there is a decline in the tidal phase from $10 \mathrm{~h}$ (LT) to $8.5 \mathrm{~h}$ (LT), and then the tidal phase returns back to its pre-SSW levels in February. Using the Whole Atmosphere Model (WAM), FullerRowell et al. (2010) also found similar changes in the phase of SW2 tide at $\sim 110 \mathrm{~km}$ at Northern Hemisphere mid latitudes during the 2009 SSW event. They suggested that the phase change in SW2 is due to the change in the propagation conditions of the atmosphere during SSWs. As the $S_{2}$ tidal variations of the EEJ are mainly driven by the SW2 tide originating from below, the modelling results of Fuller-Rowell et al. (2010) and our observations suggest that the changes in the phase of the SW2 tide due to modified atmospheric conditions during SSWs could also be causing the changes in the phase of $S_{2}$. Unlike the $S_{2}$ phase, the $L_{2}$ phase, seen in Fig. 4f, shows only minor perturbations during the 2009 SSW event, and its characteristic propagation pattern is again well observed. The uncertainty levels for the phase of $L_{2}$ and $S_{2}$ are found to be around $0.3 \mathrm{~h}$.

\subsection{2-2013 SSW event}

From the North Pole temperature and the zonal mean zonal wind data in Fig. 5c, the onset of the 2013 SSW event begins at the start of January. The North Pole temperature shows an enhancement from 2 January onwards and reaches its peak value on 6 January. In the meantime, the zonal mean zonal wind starts to decelerate and then reverses on 7 January. Thereafter it decelerates again and reaches a peak reversal on 19 January. The EEJ amplitudes (Fig. 5a), as seen in the case of previous SSWs, first weaken on 8-10 January, and after the occurrence of full moon on 11 January, they start 

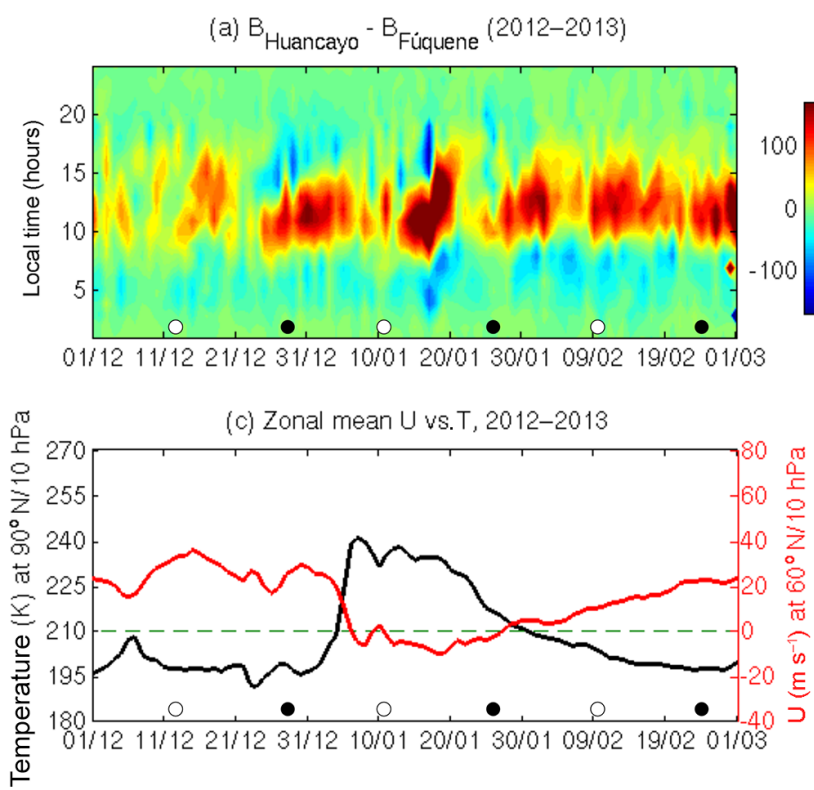

(e) Daily solar flux values, 2012-2013

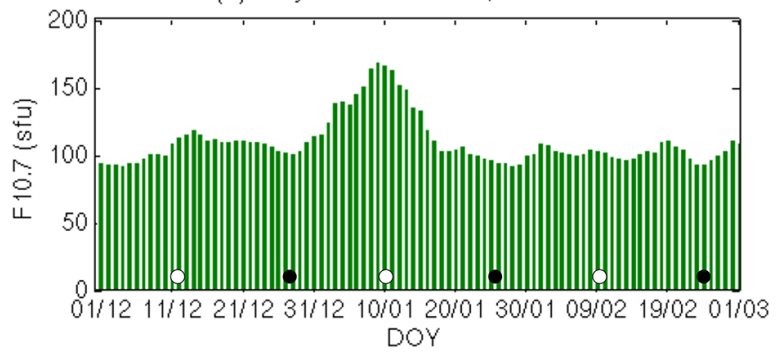

(b) Tidal amplitudes from Huancayo recordings during 2012-2013 SSW event

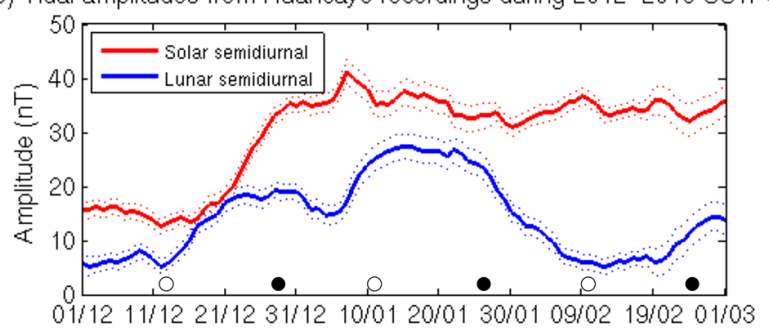

(d) Phase of the EEJ semidiurnal solar tide

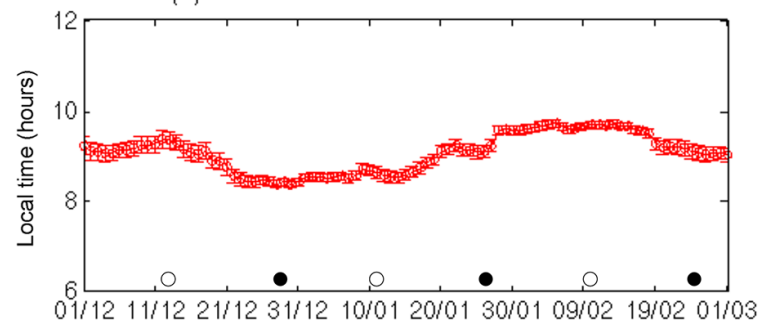

(f) Phase of the EEJ semidiurnal lunar tide

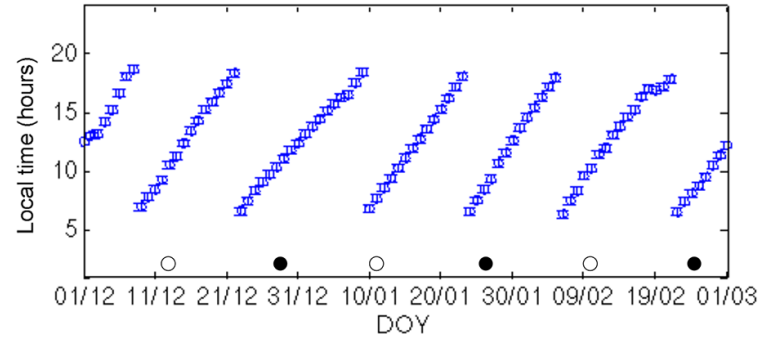

Figure 5. Same as Fig. 2, except between 1 December 2012 and 1 March 2013

to display the semidiurnal perturbation pattern. This pattern then evolves on succeeding days and can be more clearly observed on 15-20 January. The discontinuous variation and CEJ on 17 January could be related to enhanced geomagnetic activity on that day. Zhou et al. (2018) have shown that CEJ can be caused by enhancements in the geomagnetic activity levels. The reduction of the EEJ amplitudes prior to the enhanced semidiurnal pattern is similar to that of the observations of equatorial vertical drifts reported in Maute et al. (2016). In their work, they used the numerical simulation results for the 2013 SSW event to show that the amplitude of equatorial vertical drifts reduces during this event due to the phenomenon of beats between the enhanced SW2 and M2 tides. The similar periods of SW2 and M2 will produce a theoretical beating frequency of 1 / (15.13 day), and in Fig. 5a, we can observe that the days with reduced EEJ amplitudes, on either side of the enhanced semidiurnal pattern, are separated by a similar time period. As the EEJ and vertical plasma drifts are driven by the daytime eastward polarization electric fields, it is likely that the weakening of EEJ amplitudes is being caused by the beating phenomenon between the enhanced SW2 and M2 tides.
From Fig. 5b, two episodes of $L_{2}$ enhancements can be observed. The first enhancement starts during the second week of December, when the $L_{2}$ amplitude increases from $5 \mathrm{nT}$ on 12 December to a peak tidal amplitude of $19 \mathrm{nT}$ on 28 December. A stronger second enhancement starts on 6 January and reaches a peak tidal amplitude of $27 \mathrm{nT}$ on 15 January. The $S_{2}$ enhancement also starts during the same period, with its amplitude increasing from $13 \mathrm{nT}$ on 12 December to a peak amplitude of $41 \mathrm{nT}$ on 7 January. The $S_{2}$ amplitude then shows a slight decrease during the main phase of the SSW and reaches a minimum value of $31 \mathrm{nT}$ on 31 January. Thereafter it again shows an enhancement and reaches an amplitude of $37 \mathrm{nT}$ on 9 February. Compared to the three previous SSW events, the $S_{2}$ amplitude decreases more gradually for the 2013 SSW event and shows the smallest reduction during the main phase of this SSW. Like the SSWs discussed earlier, the relative enhancement of the amplitude of $L_{2}$ is also found to be greater than that of $S_{2}$ for the $2013 \mathrm{SSW}$ event. The uncertainty levels for $S_{2}$ and $L_{2}$ amplitudes during the $2013 \mathrm{SSW}$ event are found to vary around $1.5 \mathrm{nT}$.

The phase of $S_{2}$ (Fig. 5d) once again shows a slight decrease at the onset and during the SSW event, as in the case of the three previous SSWs. The phase again stabilizes fol- 
(a) SW2 amplitude in temperature (K)

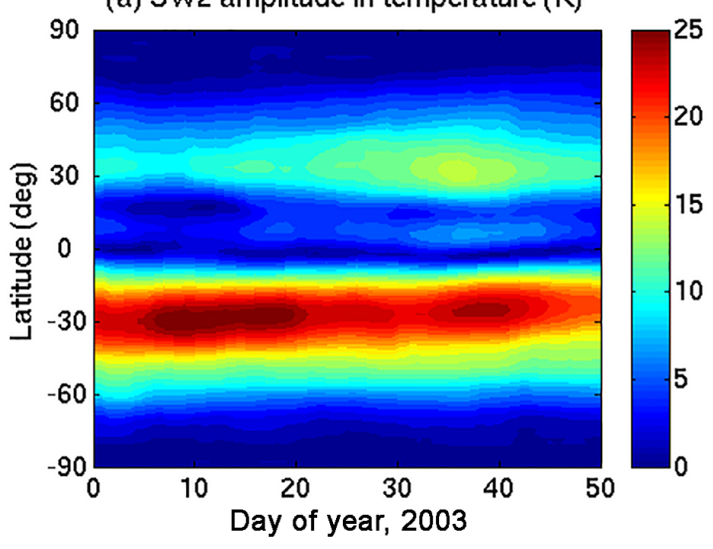

(c) SW2 amplitude in zonal wind $\left(\mathrm{m} \mathrm{s}^{-1}\right)$

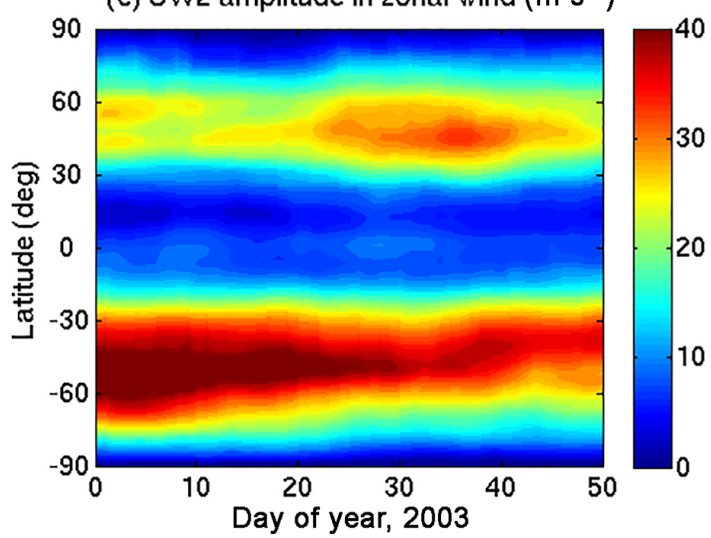

(b) SW2 phase (h)

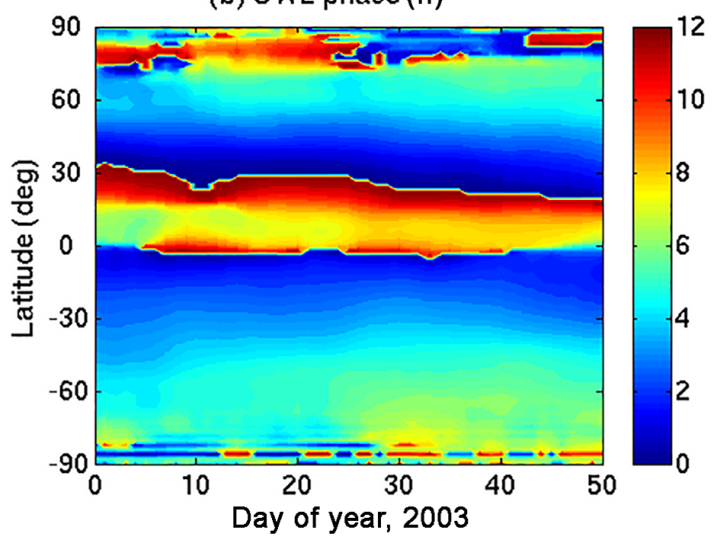

(d) SW2 phase (h)

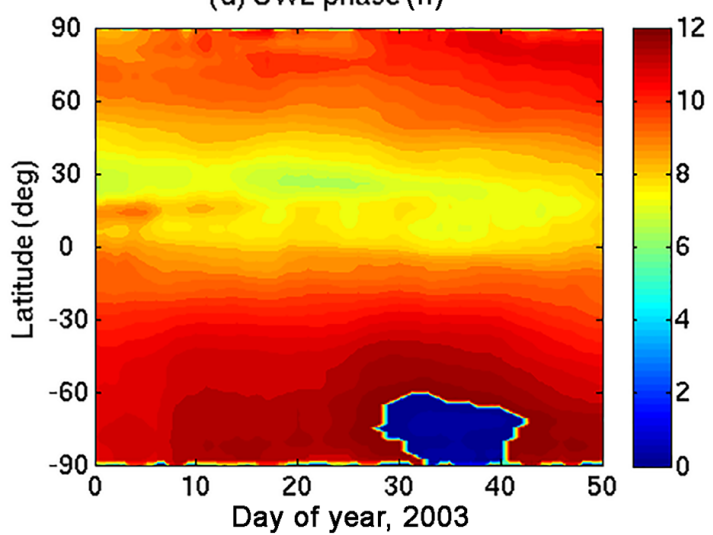

Figure 6. The SW2 tidal amplitude in neutral temperature (a) and zonal wind (c) at $\sim 120 \mathrm{~km}$ altitude during the 2002-2003 SSW event. (b) and (d) present the corresponding SW2 phase in neutral temperature and zonal wind, respectively.

lowing the peak reversal of the zonal mean zonal wind during this event. The phase of the $L_{2}$ seems to be consistent with the expected propagating phase pattern in solar time. The solar flux levels for this event, seen in Fig. 5e, range from moderate to high between December and February, with peak values around $160 \mathrm{sfu}$ being recorded during the main phase of the SSW. The uncertainty levels for the phase of $L_{2}$ and $S_{2}$ are found to be around $0.3 \mathrm{~h}$.

\section{Discussion}

The $S_{2}$ and $L_{2}$ variations in the EEJ during SSWs obtained from ground-magnetometer observations are compared with simulated variations in the SW2 and M2 tides in neutral temperature and zonal wind at $\sim 120 \mathrm{~km}$ in this section. The simulation results, which are available for the 2003, 2009 and 2013 SSW events, are utilized for this purpose. In addition, the possible mechanisms that could be responsible for the observed $S_{2}$ and $L_{2}$ variabilities of the EEJ during SSWs are discussed. The hourly neutral temperature and zonal wind that are obtained from the numerical simulations are used to estimate the components of the solar and lunar tides by performing a least-squares fit of the form

$$
\begin{aligned}
A_{0} & +\sum_{n=1}^{3} \sum_{s=-3}^{3} A_{n, s} \sin \left(\frac{2 \pi}{24} n t+s \lambda+\phi_{n, s}\right) \\
& +\sum_{s=-3}^{3} L_{s} \sin \left(\frac{2 \pi}{24} 2 t-\frac{2 \pi}{24} 2 \nu+s \lambda+\Phi_{s}\right),
\end{aligned}
$$

where $t$ is the universal time in hours, $\lambda$ is longitude, $v$ denotes the lunar age in hours, $n$ represents the harmonics of a solar day and $s$ is the zonal wave number. $A_{0}$ represents the mean value, and $A_{n, s}$ and $\phi_{n, s}$ denote the amplitude and phase of the solar tides, whereas $L_{s}$ and $\Phi_{s}$ denote the amplitude and phase of the semidiurnal lunar tide. A moving window of 21 days is used to determine the amplitudes and phases of the SW2 and the M2 tides.

For the 2002-2003 SSW event, the results from the National Center for Atmospheric Research's Whole Atmosphere Community Climate Model eXtended version with "Specified Dynamics" (SD-WACCMX; Liu et al., 2018) are used to investigate the SW2 variability. The simulations are 
forced with the NASA Modern-Era Retrospective Analysis for Research and Applications (MERRA) reanalysis from 0$50 \mathrm{~km}$. The lunar tidal forcing is not included in this simulation. Figure 6a and c depict the SW2 tidal amplitude at $\sim$ $120 \mathrm{~km}$ in neutral temperature and zonal wind, respectively, with the corresponding SW2 phases displayed in Fig. 6b and d. In Fig. 6a and c, the SW2 amplitudes show prominent amplification at mid latitudes in both hemispheres during the $2003 \mathrm{SSW}$ event. The hemispherical asymmetry in SW2 enhancements is noticeable, which could be due to the hemispheric differences in the tidal propagation conditions that result in the excitation of asymmetric tidal modes (e.g. Forbes et al., 2013). The SW2 amplitude in neutral temperature (Fig. 6a) at the mid latitudes in the Southern Hemisphere ( $\mathrm{SH}$ ) shows relatively stronger enhancements between days 6-21 and 36-41. In the Northern Hemisphere (NH), the enhancements at mid latitudes are more prominent between days 34 and 38 . SW2 maxima of $\sim 25 \mathrm{~K}$ are recorded in the $\mathrm{SH}$ on day 9 , while in the $\mathrm{NH}$ the peak amplitude is $\sim 15 \mathrm{~K}$ on day 36. The SW2 amplitude in zonal wind (Fig. 6c) shows enhancements around the similar period as the SW2 amplitude in neutral temperature. The SW2 amplitude in zonal wind shows prominent enhancements between mid and high latitudes, whereas in case of the SW2 amplitude in neutral temperature the enhancements are more prominent between low and mid latitudes. The SW2 amplitude in zonal wind in the SH shows enhancements during the whole month of January before showing a slight reduction at the end of the month and then another enhancement from day 35 . The SW2 amplitude in zonal wind in the NH shows a small amplification at the beginning of the year, which is followed by a weakening and then another amplification on days 22-45.

From Fig. 6b, it is found that the SW2 phase in neutral temperature in the $\mathrm{SH}$ does not show any major change at latitudes where the amplitude of SW2 enhances. In the NH, a clear pattern of phase change is also not evident at the latitudes where the SW2 amplitude shows major changes. From Fig. 6d, it is also apparent that the SW2 phase in zonal wind does not show any major phase change due to the SSW. Smaller phase changes of the order of $1 \mathrm{H}$ occur at mid latitudes in the $\mathrm{NH}$, but again, a clear pattern is not recognizable from these SD-WACCMX simulations.

The SW2 amplitudes in neutral temperature and zonal wind in the NH show enhancements around day 0 and day 36 , and in between this period, the SW2 tidal amplitudes are slightly weaker. The EEJ $S_{2}$ enhancements for the 2003 event resemble this variability, with maxima at the beginning and at the end of January and with reduced amplitudes in between. However, the EEJ $S_{2}$ variations do not exactly correspond with the variations of SW2 in neutral temperature and zonal wind in the SH. Based on the presented analysis, we conclude that the day-to-day variation of EEJ $S_{2}$ amplitudes during the 2003 SSW cannot be fully explained by the day-to-day variation of SW2 tidal amplitudes obtained from simulation results at dynamo-region heights.
For the 2008-2009 SSW event, we use the simulations described in Pedatella et al. (2018b) to investigate the thermospheric SW2 and M2 tidal amplification. The modelling output was obtained using the Whole Atmosphere Community Climate Model eXtended version (WACCMX; for details, see Liu et al., 2018) in which the lower and middle atmosphere variability was constrained using the ensemble adjustment Kalman filter from the Data Assimilation Research Testbed (DART). In this simulation, an additional M2 forcing term is included in the model physics (Pedatella et al., 2012). The SW2 and M2 tides in neutral temperature at $\sim 120 \mathrm{~km}$ are depicted in Fig. 7. The SW2 amplitude (Fig. 7a) at mid latitudes in the SH shows an enhancement in the first week of January, which is then followed by a reduction between days 15 and 20 and a second enhancement between days 20 and 40 . In the $\mathrm{NH}$, the $\mathrm{SW} 2$ enhancement is only prominent between days 20 and 40 . The M2 enhancements can be observed in Fig. 7c on days 20-30 and days 35-45. The M2 amplitudes show a hemispherical asymmetry, with the highest values occurring in the $\mathrm{NH}$. The SW2 and M2 tides in zonal wind at $\sim 120 \mathrm{~km}$ for the 2008-2009 SSW event are depicted in Fig. 8. The SW2 tidal enhancements in zonal wind (Fig. 8a) are similar to the SW2 enhancements in neutral temperature (Fig. 7a) in temporal terms for the 2009 SSW event as well, but again, a difference in the latitudinal structures in Figs. 7a and 8a can be observed. The amplification in SW2 in zonal wind occurs at higher latitudes in both the hemispheres, as compared to the amplification of SW2 in neutral temperature. The phase of SW2 in neutral temperature (Fig. 7b) and zonal wind (Fig. 8b) show a noticeable decrease in the $\mathrm{NH}$ just prior to the start of the SW2 amplification in the NH around day 20. The phase of SW2 in neutral temperature (Fig. 7b) decreases by $1 \mathrm{~h}$ during this period, whereas the SW2 phase in zonal wind (Fig. 8b) decreases by more than $2 \mathrm{~h}$ during this period. The SW2 phase then returns back to original levels after day 30 in both Figs. $7 \mathrm{~b}$ and $8 \mathrm{~b}$. This result is consistent with the findings of Pedatella et al. (2014), in which the decrease of the phase of SW2 tide in neutral temperature during the 2009 SSW event was reported using the results from four different general circulation models.

At a fixed latitude, the phase of M2 in neutral temperature (Fig. 7d) and zonal wind (Fig. 8d) shows the characteristic propagation pattern, where the phase repeats after an interval of 14.77 days. The phase of M2 derived from neutral temperature (Fig. 7d) shows some major changes at mid and high latitudes, at the time when the SW2 phase in neutral temperature decreases at low and mid latitudes, but the M2 phase in zonal wind (Fig. 8d) does not show any major variation during this same period. The actual impact of SSW conditions on the phase of M2 tide is difficult to uncover from these plots, and more comparisons between the M2 tide during SSW and non-SSW conditions are needed to address this issue.

The timing of the first $S_{2}$ enhancement of the EEJ (Fig. 4b) and its reduction are seen to coincide with the SW2 am- 

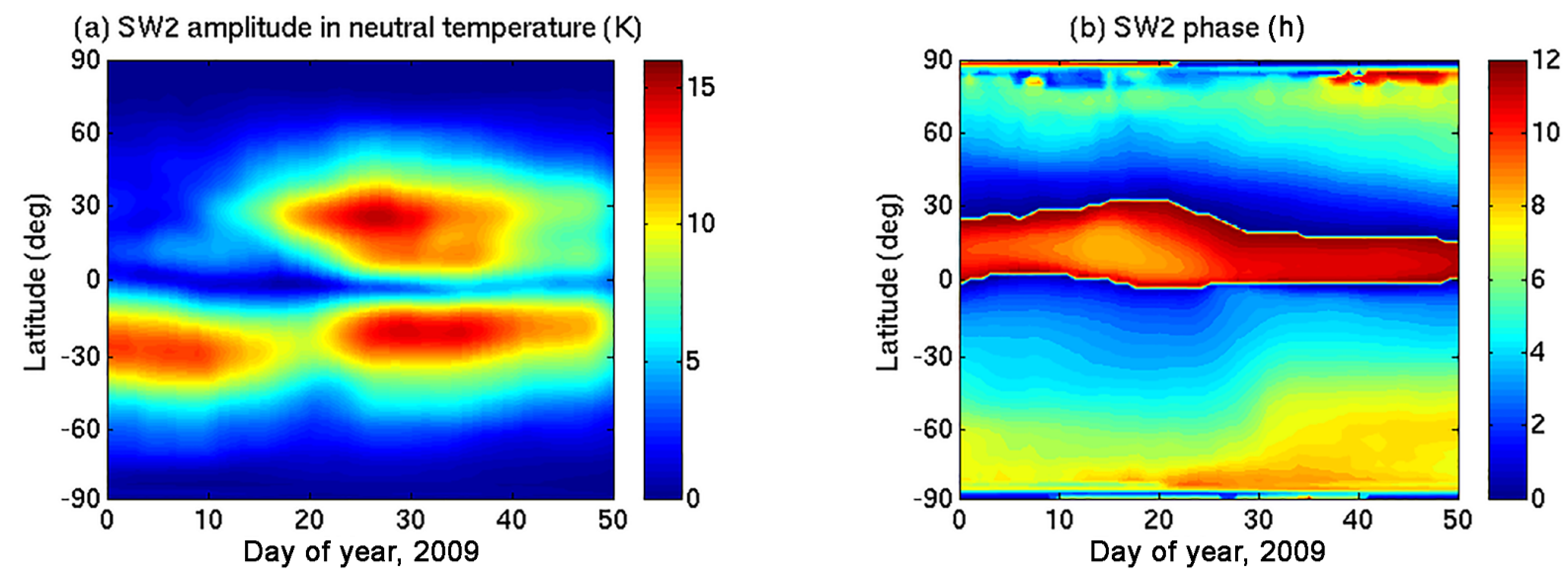

(c) M2 amplitude in neutral temperature (K)
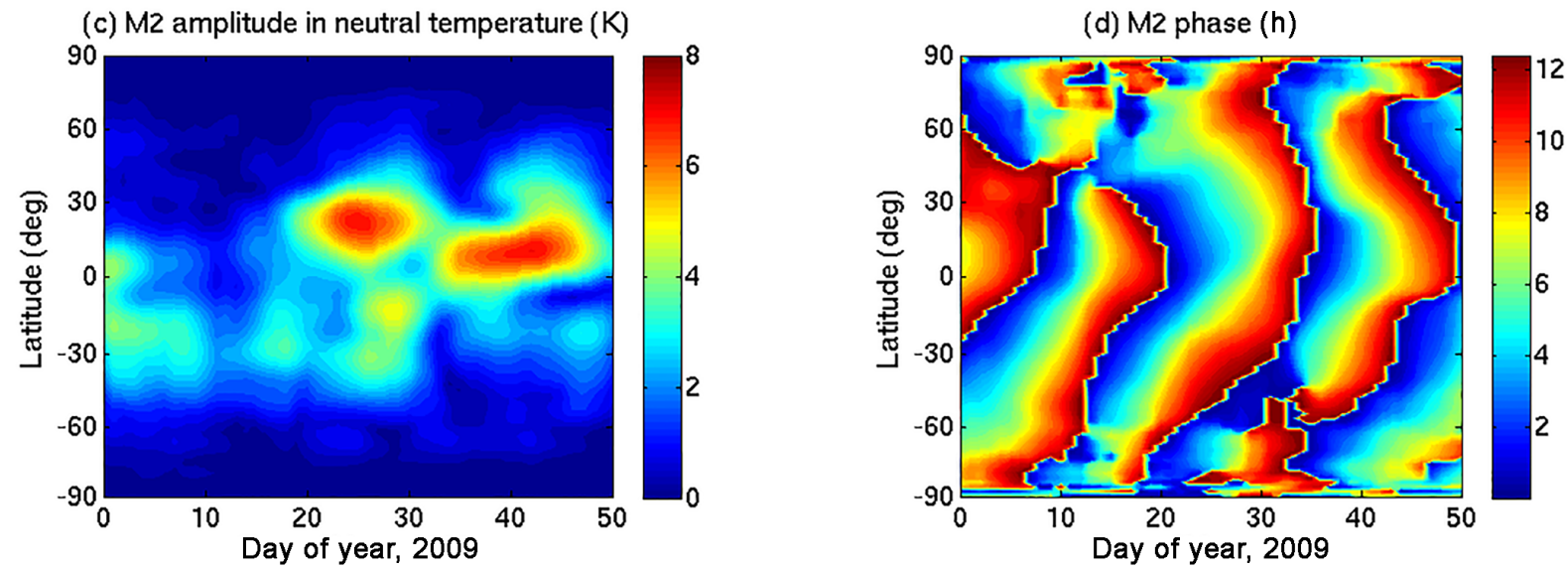

Figure 7. The amplitude (a) and phase (b) of the SW2 tide in neutral temperature at $\sim 120 \mathrm{~km}$ altitude during the 2008-2009 SSW event (simulations from Pedatella et al., 2018a). The amplitude and phase of the M2 tide during the same period are presented in (c) and (d), respectively.

plitudes in neutral temperature and zonal wind in the SH. The timing of the second SW2 enhancement that is seen in both hemispheres also shows a good agreement with the $S_{2}$ enhancements over Huancayo. Compared to the 2003 SSW event, the SW2 amplitude for the 2009 SSW event shows a better agreement with the EEJ $S_{2}$ enhancements. Comparing the amplification of the M2 amplitude in neutral temperature and zonal wind and the $L_{2}$ at Huancayo (Fig. 4b), it is observed that the enhancements occur around the same period.

For the 2012-2013 SSW, the SW2 and M2 tides are investigated using the modelling results of Maute et al. (2016). In their work, the NCAR thermosphere-ionospheremesosphere-electrodynamics general circulation (TIMEGCM) model was nudged toward WACCMX with specified meteorology (SM) from the Goddard Earth Observing System Data Assimilation System version 5 (GEOS-5) zonal mean simulation results in the lower and middle atmosphere. More details about this nudging approach can be found in Maute et al. (2015). The M2 and N2 (lunar elliptic semidiurnal tide) lunar tidal perturbations based on the global scale wave model (GSWM-09; Zhang et al., 2010) are included in this simulation. Figures 9 and 10 depict the amplitudes and phases of the SW2 and M2 tides in neutral temperature and zonal wind at $\sim 120 \mathrm{~km}$, respectively. Despite using a different temporal window for the tidal fitting, these results are consistent with the findings of Maute et al. (2016). In Fig. 9a, the SW2 tidal amplitudes in neutral temperature are presented, and the hemispheric asymmetry in SW2 enhancements is once again noticeable. The SW2 tidal amplification in the SH is seen at mid latitudes all throughout January, while in the NH the SW2 amplification at mid latitudes starts only after day 10 . The peak amplification occurs simultaneously in both the hemispheres on day 23 . The M2 tidal amplification seen in Fig. 9c also shows hemispherical asymmetry, with the amplitudes in the SH being almost twice as large as in the NH. The M2 amplitude enhances on days 10-20, and its peak value is seen on day 16 in both hemispheres. As in the case of the 2009 SSW event, the SW2 (Fig. 10a) and M2 (Fig. 10c) amplitudes in zonal wind for the 2013 event also show temporal similarity with the SW2 (Fig. 9a) 
(a) SW2 amplitude in zonal wind $\left(\mathrm{m} \mathrm{s}^{-1}\right)$

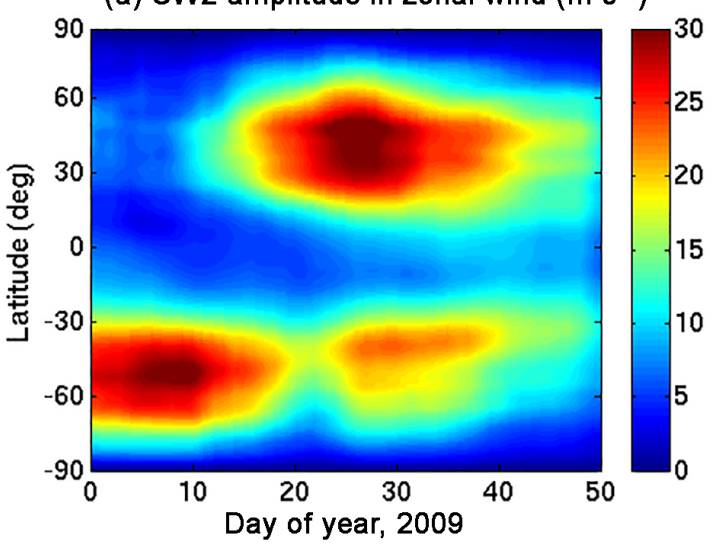

(c) M2 amplitude in zonal wind $\left(\mathrm{m} \mathrm{s}^{-1}\right)$

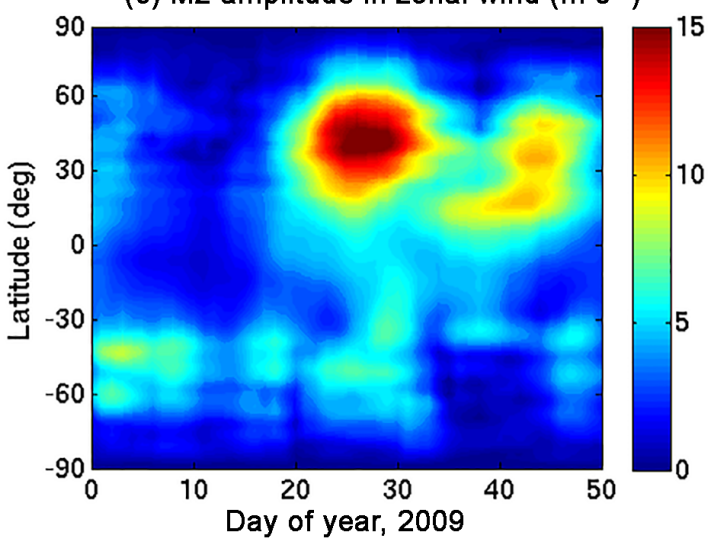

(b) SW2 phase (h)

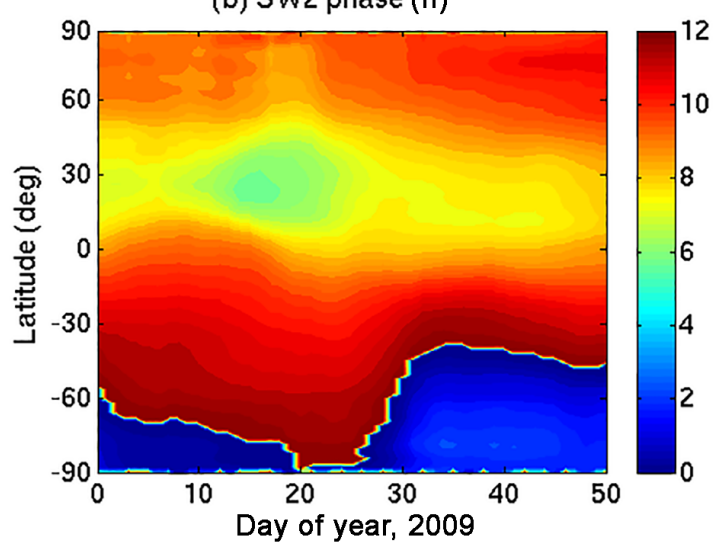

(d) M2 phase (h)

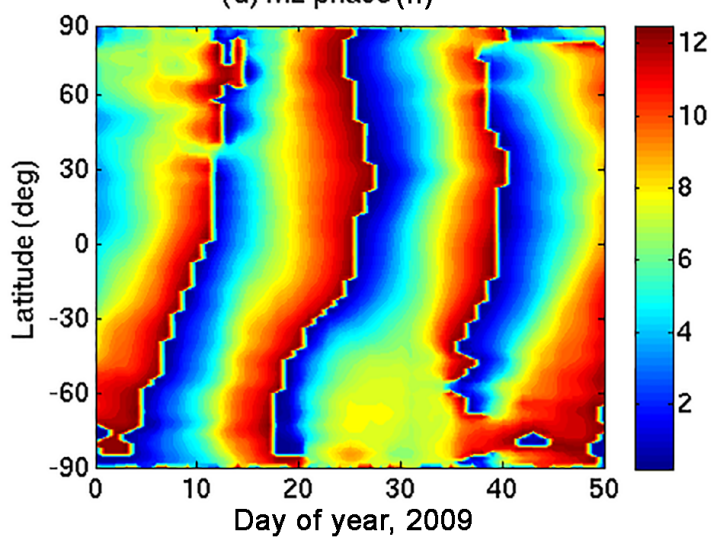

Figure 8. The amplitude (a) and phase (b) of the SW2 tide in zonal wind at $\sim 120 \mathrm{~km}$ altitude during the 2008-2009 SSW event (simulations from Pedatella et al., 2018a). The amplitude and phase of the M2 tide during the same period are presented in (c) and (d), respectively.

and M2 (Fig. 9c) amplitudes in neutral temperature, but the amplification of these tides does not occur at the same latitudes in these figures. From the phase plots of the SW2 tide in neutral temperature (Fig. 9b) and zonal wind (Fig. 10b), it is found that at both mid and high latitudes in both the hemispheres, the SW2 phase shows a slight decrease prior to the start of the SW2 amplitude enhancements from day 18. For the M2 tide, the phase plots for neutral temperature (Fig. 9d) and zonal wind (Fig. 10d) do not reveal any major changes due to SSW conditions. For a fixed latitude, the day-to-day M2 tidal phase propagation is again well reproduced in both these figures.

The comparison between the timing of M2 enhancements in neutral temperature and zonal wind and the EEJ $L_{2}$ enhancements at Huancayo (Fig. 5b) shows that they coincide with each other, which is not exactly the case with the solar semidiurnal enhancements. The peak SW2 enhancements in neutral temperature occur a few days later than the EEJ $S_{2}$ enhancements over Huancayo. The semidiurnal tidal amplitudes in neutral temperature and zonal wind for the 2013 SSW event are comparably larger than those corre- sponding to the other two SSW events, and absolute comparisons in semidiurnal tidal amplitudes among the three SSWs should be avoided. The difference exists due to the different models and the different forcing methods that are used to produce the simulation outputs. The tidal amplitudes in WACCMX are known to be damped (e.g. Pedatella et al., 2018b) in order to stabilize the model, however, for the 2013 SSW simulation, WACCMX/GEOS-5 was employed with reduced damping, which probably led to an overestimation of the semidiurnal tides (Maute et al., 2016).

The 2009 and 2013 SSW model simulations from Pedatella et al. (2018b) and Maute et al. (2016), respectively, reproduced the salient features of the $E \times B$ drifts seen from radar observations. We therefore find it reasonable to compare the EEJ semidiurnal tidal enhancements with the simulated semidiurnal tidal enhancements in neutral temperature and zonal wind at the E-region heights. From the simulation and observation results, we find that the timing of the M2 amplification in neutral temperature and zonal wind shows a better agreement with the $L_{2}$ amplification in the EEJ, as compared to the case of SW2 amplification during the 2009 

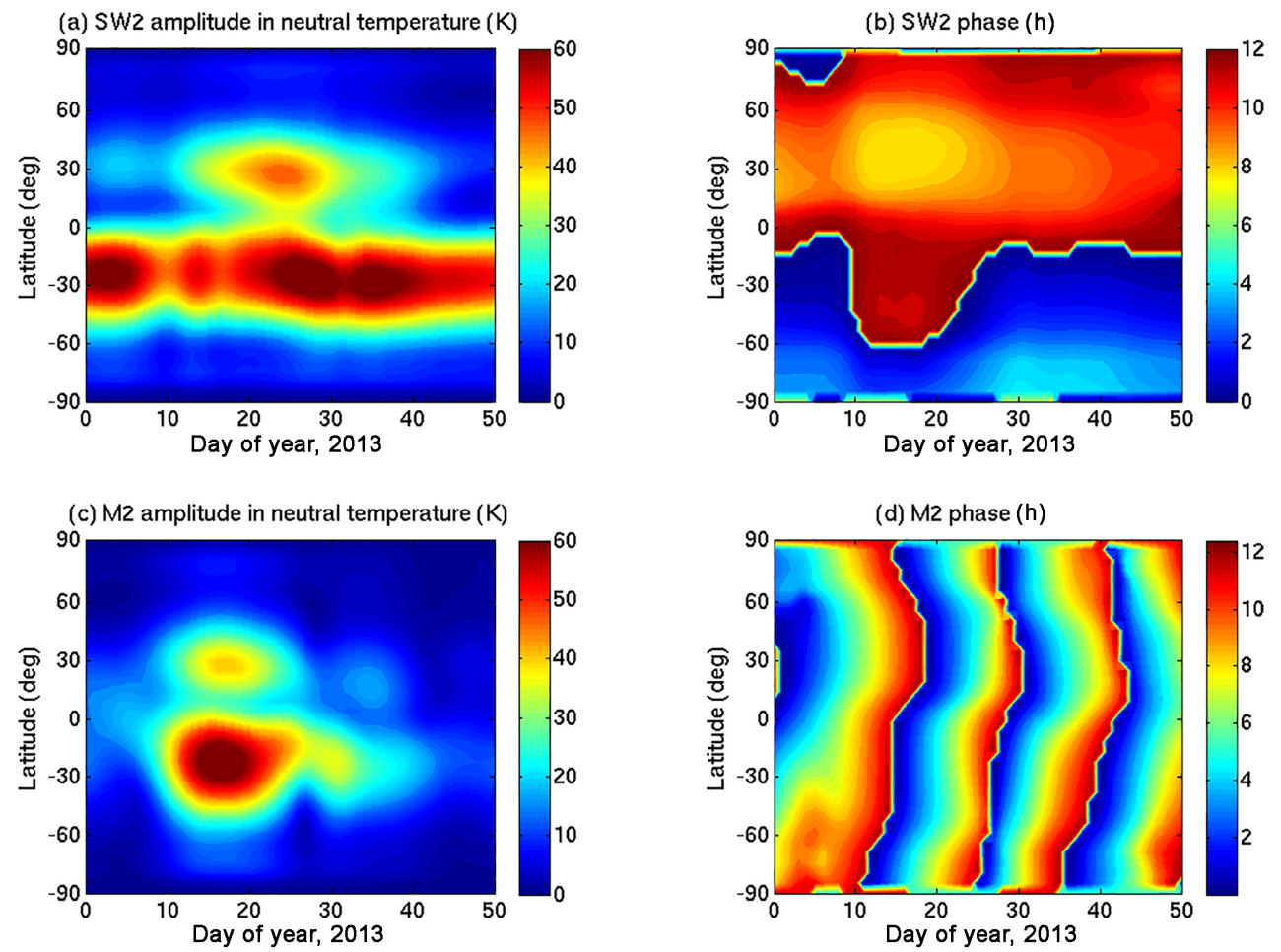

Figure 9. Same as Fig. 7, except for the 2012-2013 SSW event (simulations from Maute et al., 2016).

and 2013 SSWs. It is also important to note that the peak enhancements in $\mathrm{M} 2$ and $L_{2}$ occur on the same day during these two events. The mechanism of the M2 enhancement during SSWs has been explained by Forbes and Zhang (2012) through the shifting of the so-called Pekeris resonance peak of the atmosphere towards the M2 lunar period. The resonance peak shifts due to the changes in the zonal mean temperature and wind structure of the middle atmosphere during SSWs. The enhanced M2 amplitudes at dynamo-region heights drive an enhanced lunar current system in the ionosphere during SSWs (Yamazaki, 2014) and lead to an enhancement of $L_{2}$ variations in the EEJ.

The asymmetrical SW2 enhancements during the 2003, 2009 and 2013 SSWs suggest that the asymmetrical tidal modes are important for understanding the SW2 tidal variability during SSWs. Jin et al. (2012) used the Ground-totopside model of Atmosphere and Ionosphere for Aeronomy (GAIA) to investigate the SW2 Hough modes, which were derived from the neutral temperature at $116 \mathrm{~km}$, during the 2009 SSW event, and found the largest temporal variations in the symmetric semidiurnal $(2,2)$ and the asymmetric semidiurnal $(2,3)$ modes (see Fig. 9; Jin et al., 2012). The enhancement of asymmetric solar tidal modes also causes major changes in the structure of the ionospheric solar quiet current systems during SSWs (Yamazaki, 2014). However, as the wavelengths of the asymmetric solar tidal modes at dynamo-region heights are much smaller than those of the symmetric solar tidal modes (e.g. Stening, 1969; Tarpley, 1970; Stening, 1989), their effectiveness in generating currents in the ionosphere is smaller than in the case of the symmetrical tidal modes (Stening, 1969). The EEJ solar tidal changes during SSWs are therefore more likely to be caused by the variability of the symmetrical solar tidal modes. This could be one of the reasons for the lack of agreement between the SW2 tidal enhancements in neutral temperature and zonal wind and $S_{2}$ of the EEJ.

To explain the changes in the SW2 at the mesospheric and thermospheric altitudes due to SSWs, a number of mechanisms have been proposed through both observation and modelling studies. Pedatella and Forbes (2010) investigated the 2009 SSW event and suggested that the changing mean wind conditions in the MLT during the SSW and post-SSW period could be a reason for the reduction and enhancement of the SW2 amplitudes in GPS total electron content (TEC) observations. Wang et al. (2011) proposed the nonlinear wave-wave interactions of migrating solar diurnal (DW1), semidiurnal (SW2) and terdiurnal (TW3) tides as the reason for the decrease of SW2 amplitudes in the ionospheric E-region during the 2009 SSW event. They suggested that the DW1, SW2 and TW3 form a resonant triad, and a direct wave-wave interaction among these tides may lead to a rapid growth in one of the tides at the expense of other two. Based on their results, they concluded that the SW2 tide was losing energy to the TW3 tide, resulting in the amplification of the 
(a) SW2 amplitude in zonal wind $\left(\mathrm{m} \mathrm{s}^{-1}\right)$

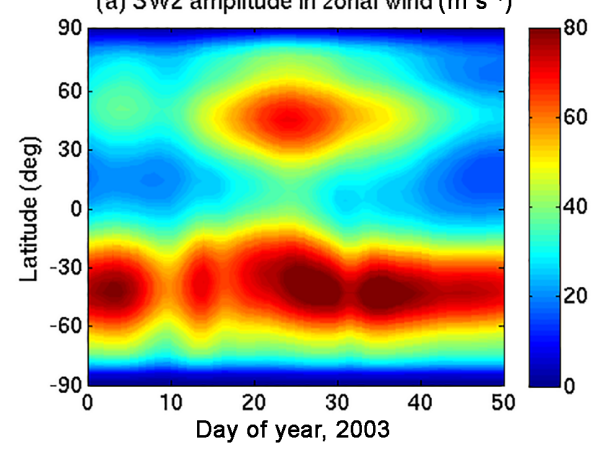

(c) M2 amplitude in zonal wind $(\mathrm{m} / \mathrm{s})$

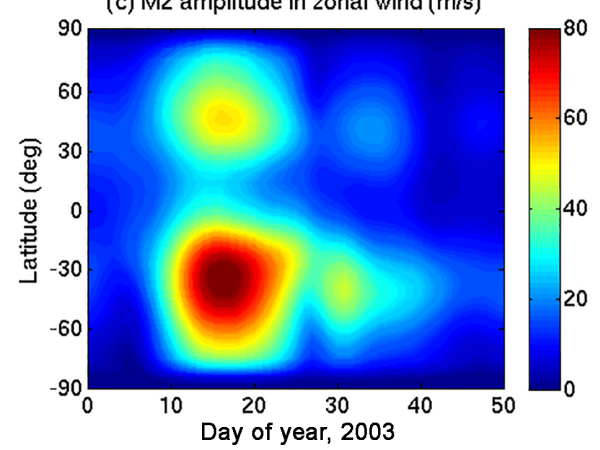

(b) SW2 phase (h)

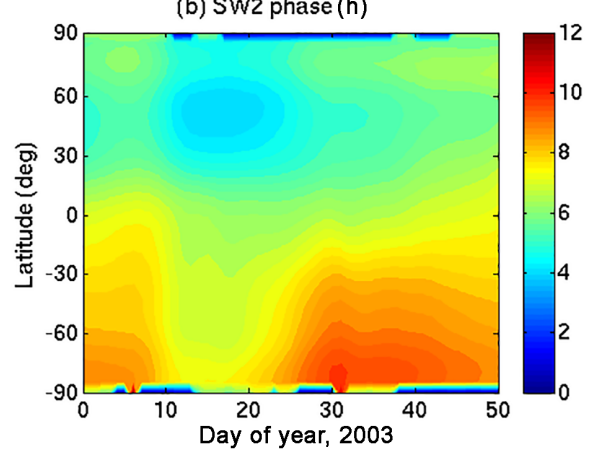

(d) M2 phase (hфur)

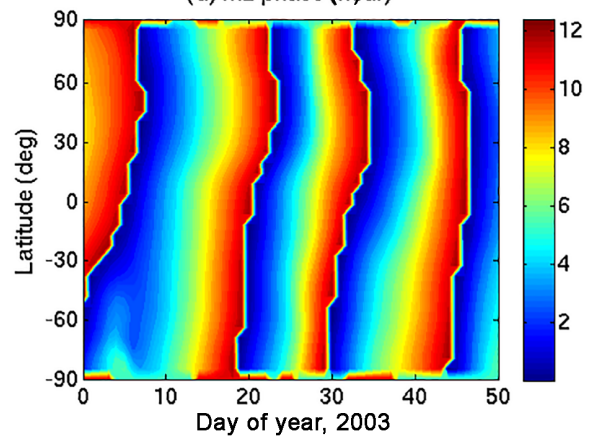

Figure 10. Same as Fig. 8 except for the 2012-2013 SSW event (simulations from Maute et al., 2016).

latter during the 2009 SSW. Maute et al. (2015), however, did not find a significant variation in the simulated TW3 tidal amplitude during the 2013 SSW event.

The SW2 amplitudes in the MLT and upper thermosphere may also be affected by the redistribution of ozone during SSWs (e.g. Goncharenko et al., 2012; Sridharan et al., 2012). In case of the 2009 SSW event, Goncharenko et al. (2012) noted that the ozone levels in the tropical stratosphere increased immediately after the SSW, and this could lead to the enhancement of the SW2 tide, as ozone is a major excitation source of the SW2 tide (e.g. Lindzen and Chapman, 1969). A modelling study by Jin et al. (2012) proposed that the changes in the structure of the zonal mean zonal wind and the meridional temperature gradient in the middle atmosphere during SSWs lead to a change in the tidal propagation conditions and could result in the amplification of the SW2 tide in the MLT and upper thermosphere.

Numerical studies by McLandress (2002) showed that the amplitude of the DW1 in the MLT can become amplified if there is an enhancement of the meridional wind shear in the upper atmosphere. A meridional shear in the eastward (westward) direction in the $\mathrm{NH}$ broadens (narrows) the tropical waveguide of the tides. Sassi et al. (2013) used this hypothesis to show that the decrease in the amplitude of the SW2 tide resulted from the increase in the westward meridional shear in the MLT during the 2009 SSW event. Another mechanism that has been proposed to explain the SW2 tidal changes dur- ing SSWs is the nonlinear planetary wave-tide interaction between the stationary planetary waves and SW2 (Liu et al., 2010). Simulation results of the 2006 SSW event by Maute et al. (2014) confirmed an increase in SW1 and a decrease in SW2 in the E-region due to the non-linear wave-tide interactions between the SW2 and planetary wave number 1 during this event.

It is likely that a combination of the aforementioned mechanisms is responsible for the observed SW2 variability at ionospheric altitudes. The SSW-induced changes in the SW2 drive the variability in the $S_{2}$ of the EEJ during SSWs through the ionospheric dynamo mechanism. The global reduction and amplification in the SW2 amplitudes during the SSWs as seen at ionospheric altitudes is therefore also reflected in the $S_{2}$ variations of the EEJ. However, more research is needed for completely understanding the role of symmetrical and asymmetrical solar tidal modes in causing the solar tidal variability of the EEJ during SSWs. In addition, the relative importance of the mechanisms responsible for the changes in SW2 during SSWs also needs to be studied.

\section{Conclusions}

In this study, we have used the ground-magnetic field recordings at the Huancayo and Fúquene observatories to determine the semidiurnal solar and lunar tidal variability of the EEJ 
during the 2003, 2006, 2009 and 2013 major SSWs. The solar and lunar tidal variabilities are then compared with the timing of the occurrence of the SSWs. The comparison between the EEJ semidiurnal solar and lunar tidal changes and the migrating semidiurnal solar (SW2) and lunar (M2) tides in neutral temperature and zonal wind, which are obtained from different numerical simulations at E-region heights, have also been performed. The major conclusions derived from this study are as follows.

1. The semidiurnal lunar tide of the EEJ shows major amplification during all four SSW events, and its amplitude is observed to become comparable or even greater than the semidiurnal solar tidal amplitude. In addition, the relative amplification of the EEJ lunar semidiurnal tide is seen to be larger than that of the EEJ solar semidiurnal tide during all four SSWs.

2. The EEJ semidiurnal solar tidal amplitude shows an enhancement prior to the onset of the SSWs, which is then followed by a reduction during the deceleration of the zonal mean zonal wind and then a subsequent enhancement when the zonal mean zonal wind starts to recover after its peak reversal.

3. The timing of the global M2 enhancements in neutral temperature and zonal wind at $\sim 120 \mathrm{~km}$ and that of the EEJ semidiurnal lunar tidal enhancements during SSWs show a good agreement with each other. In the case of a similar comparison between the SW2 and the EEJ semidiurnal solar tidal enhancements, the degree of agreement varies for each of the SSW events.

Data availability. The data from the geomagnetic observatories can be accessed freely from the website of the World Data Centre for Geomagnetism, Edinburgh (http://www.wdc.bgs.ac.uk/data. html, Reay et al., 2013). The F10.7 data can be accessed at https://omniweb.gsfc.nasa.gov/ (King and Papitashvil, 2005). The NCEP/NCAR reanalysis data are available at https://www.esrl. noaa.gov/psd/data/ (Kalnay et al., 1996). The international quiet days are available at https://www.gfz-potsdam.de/en/kp-index/ (Menvielle and Berthelier, 1991). The simulation data used in this paper are stored in the NCAR repositories and can be provided on request.

Author contributions. All the authors contributed to the design and implementation of the research, to the analysis of the results and to the writing of the manuscript.

Competing interests. The authors declare that they have no conflict of interest.

Special issue statement. This article is part of the special issue "Dynamics and interaction of processes in the Earth and its space environment: the perspective from low Earth orbiting satellites and beyond". It is not associated with a conference.

Acknowledgements. We would like to thank the Instituto Geofisico del Peru and Instituto Geográfico Agustin Codazzi, Colombia, for supporting geomagnetic observatory operations at Huancayo and Fúquene, respectively. The F10.7 data are obtained from NASA GSFC/SPDF OMNIWeb. The NCEP/NCAR reanalysis data are available at the NOAA/OAR/ESRL website. The list of international quiet days are available from GFZ Potsdam. Claudia Stolle and Hermann Lühr are partly supported by SPP 1788 "Dynamic Earth" of the Deutsche Forschungsgemeinschaft (DFG). Yosuke Yamazaki was supported by the Humboldt Research Fellowship for Experienced Researchers from the Alexander von Humboldt Foundation. The National Center for Atmospheric Research is sponsored by National Science Foundation. Tarique A. Siddiqui and Astrid Maute are supported by NASA grant X13AF77G. We would like to acknowledge high-performance computing support from Cheyenne (https://doi.org/10.5065/D6RX99HX), provided by the NCAR's Computational and Information Systems Laboratory and sponsored by the National Science Foundation.

Edited by: Jorge Luis Chau

Reviewed by: two anonymous referees

\section{References}

Alken, P. and Maus, S.: Spatio-temporal characterization of the equatorial electrojet from CHAMP, Ørsted, and SAC-C satellite magnetic measurements, J. Geophys. Res.-Space, 112, A09305, https://doi.org/10.1029/2007JA012524, 2007.

Andrews, D. G., Holton, J. R., and Leovy, C. B.: Middle atmosphere dynamics, 40, Academic press, 1987.

Baker, W. and Martyn, D. F.: Electric currents in the ionosphereThe conductivity, Philos. T. R. Soc. Lond. S-A, 246, 281-294, 1953.

Bartels, J. and Johnston, H.: Geomagnetic tides in horizontal intensity at Huancayo, Terrestrial Magnetism and Atmospheric Electricity, 45, 269-308, https://doi.org/10.1029/TE045i003p00269, 1940.

Chandran, A. and Collins, R. L.: Stratospheric sudden warming effects on winds and temperature in the middle atmosphere at middle and low latitudes: a study using WACCM, Ann. Geophys., 32, 859-874, https://doi.org/10.5194/angeo-32-859-2014, 2014.

Chapman, S.: The equatorial electrojet as detected from the abnormal electric current distribution above Huancayo, Peru, and elsewhere, Meteorol. Atmos. Phys., 4, 368-390, https://doi.org/10.1007/BF02246814, 1951.

Charlton, A. J. and Polvani, L. M.: A new look at stratospheric sudden warmings, Part I: Climatology and modeling benchmarks, J. Clim., 20, 449-469, https://doi.org/10.1175/JCLI3996.1, 2007.

Chau, J., Fejer, B. G., and Goncharenko, L.: Quiet variability of equatorial $E \times B$ drifts during a sudden stratospheric warming event, Geophys. Res. Lett., 36, L05101, https://doi.org/10.1029/2008GL036785, 2009. 
Chau, J. L., Goncharenko, L. P., Fejer, B. G., and Liu, H.-L.: Equatorial and Low Latitude Ionospheric Effects During Sudden Stratospheric Warming Events, Space Sci. Rev., 168, 385-417, https://doi.org/10.1007/s11214-011-9797-5, 2012.

Chau, J. L., Hoffmann, P., Pedatella, N. M., Matthias, V., and Stober, G.: Upper mesospheric lunar tides over middle and high latitudes during sudden stratospheric warming events, J. Geophys. Res.Space, 120, 3084-3096, https://doi.org/10.1002/2015JA020998, 2015.

Conte, J. F., Chau, J. L., Stober, G., Pedatella, N., Maute, A., Hoffmann, P., Janches, D., Fritts, D., and Murphy, D. J.: Climatology of semidiurnal lunar and solar tides at middle and high latitudes: Interhemispheric comparison, J. Geophys. Res.-Space, 122, 7750-7760, 2017.

Cowling, T. G.: The electrical conductivity of an ionised gas in the presence of a magnetic field, Mon. Not. R. Astron. Soc., 93, 9097, https://doi.org/10.1093/mnras/93.1.90, 1932.

Fang, T.-W., Fuller-Rowell, T., Akmaev, R., Wu, F., Wang, H., and Anderson, D.: Longitudinal variation of ionospheric vertical drifts during the 2009 sudden stratospheric warming, J. Geophys. Res.-Space, 117, A03324, https://doi.org/10.1029/2011JA017348, a03324, 2012.

Fejer, B. G., Olson, M. E., Chau, J. L., Stolle, C., Lühr, H., Goncharenko, L. P., Yumoto, K., and Nagatsuma, T.: Lunardependent equatorial ionospheric electrodynamic effects during sudden stratospheric warmings, J. Geophys. Res.-Space, 115, A00G03, https://doi.org/10.1029/2010JA015273, 2010.

Forbes, J. M. and Zhang, X.: Lunar tide amplification during the January 2009 stratosphere warming event: Observations and theory, J. Geophys. Res.-Space, 117, A12312, https://doi.org/10.1029/2012JA017963, 2012.

Forbes, J. M., Zhang, X., Bruinsma, S., and Oberheide, J.: Lunar semidiurnal tide in the thermosphere under solar minimum conditions, J. Geophys. Res.-Space, 118, 1788-1801, 2013.

Fritz, S. and Soules, S.: Large-scale temperature changes in the stratosphere observed from Nimbus III, J. Atmos. Sci., 27, 10911097, 1970.

Fuller-Rowell, T., Wu, F., Akmaev, R., Fang, T.-W., and AraujoPradere, E.: A whole atmosphere model simulation of the impact of a sudden stratospheric warming on thermosphere dynamics and electrodynamics, J. Geophys. Res.-Space, 115, A00G08, https://doi.org/10.1029/2010JA015524, 2010.

Funke, B., López-Puertas, M., Bermejo-Pantaleón, D., GarcíaComas, M., Stiller, G. P., von Clarmann, T., Kiefer, M., and Linden, A.: Evidence for dynamical coupling from the lower atmosphere to the thermosphere during a major stratospheric warming, Geophys. Res. Lett., 37, L13803, https://doi.org/10.1029/2010GL043619, 113803, 2010.

Garcia, R. R.: On the mean meridional circulation of the middle atmosphere, J. Atmos. Sci., 44, 3599-3609, 1987.

Goncharenko, L. and Zhang, S.-R.: Ionospheric signatures of sudden stratospheric warming: Ion temperature at middle latitude, Geophys. Res. Lett., 35, L21103, https://doi.org/10.1029/2008GL035684, 121103, 2008.

Goncharenko, L. P., Coster, A. J., Chau, J. L., and Valladares, C. E.: Impact of sudden stratospheric warmings on equatorial ionization anomaly, J. Geophys. Res.-Space, 115, A00G07, https://doi.org/10.1029/2010JA015400, a00G07, 2010.
Goncharenko, L. P., Coster, A. J., Plumb, R. A., and Domeisen, D. I. V.: The potential role of stratospheric ozone in the stratosphereionosphere coupling during stratospheric warmings, Geophys. Res. Lett., 39, L08101, https://doi.org/10.1029/2012GL051261, 2012.

Haynes, P. H., McIntyre, M. E., Shepherd, T. G., Marks, C. J., and Shine, K. P.: On the "Downward Control" of Extratropical Diabatic Circulations by Eddy-Induced Mean Zonal Forces, J. Atmos. Sci., 48, 651-678, https://doi.org/10.1175/15200469(1991)048<0651:OTCOED>2.0.CO;2, 1991.

Heelis, R.: Electrodynamics in the low and middle latitude ionosphere: A tutorial, J. Atmos. Sol.-Terr. Phys., 66, 825-838, 2004.

Jin, H., Miyoshi, Y., Pancheva, D., Mukhtarov, P., Fujiwara, H., and Shinagawa, H.: Response of migrating tides to the stratospheric sudden warming in 2009 and their effects on the ionosphere studied by a whole atmosphere-ionosphere model GAIA with COSMIC and TIMED/SABER observations, J. Geophys. Res.-Space, 117, A10323, https://doi.org/10.1029/2012JA017650, 2012.

Kalnay, E., Kanamitsu, M., Kistler, R., Collins, W., Deaven, D., Gandin, L., Iredell, M., Saha, S., White, G., Woollen, J., Zhu, Y., Chelliah, M., Ebisuzaki, W., Higgins, W., Janowiak, J., Mo, K. C., Ropelewski, C., Wang, J., Leetmaa, A., Reynolds, R., Jenne, R., and Joseph, D.: The NCEP/NCAR 40-Year Reanalysis Project, Bull. Am. Meteorol. Soc., 77, 437-472, https://doi.org/10.1175/1520 0477(1996)077<0437:TNYRP>2.0.CO;2, 1996.

Karlsson, B., McLandress, C., and Shepherd, T. G.: Interhemispheric mesospheric coupling in a comprehensive middle atmosphere model, J. Atmos. Sol.-Terr. Phys., 71, 518-530, 2009.

King, J. H. and Papitashvili, N. E.: Solar wind spatial scales in and comparisons of hourly Wind and ACE plasma and magnetic field data, J. Geophys. Res., 110, A02209, https://doi.org/10.1029/2004JA010649, 2005.

Körnich, H. and Becker, E.: A simple model for the interhemispheric coupling of the middle atmosphere circulation, Adv. Space Res., 45, 661-668, 2010.

Labitzke, K.: Temperature Changes in the Mesosphere and Stratosphere Connected with Circulation Changes in Winter, J. Atmos. Sci., 29, 756-766, https://doi.org/10.1175/15200469(1972)029<0756:TCITMA>2.0.CO;2, 1972.

Lin, C., Lin, J., Chang, L., Chen, W., Chen, C., and Liu, J.: Stratospheric sudden warming effects on the ionospheric migrating tides during 2008-2010 observed by FORMOSAT-3/COSMIC, J. Atmos. Sol.-Terr. Phys., 103, 66-75, 2013.

Lindzen, R. S. and Chapman, S.: Atmospheric tides, Space Sci. Rev., 10, 3-188, 1969.

Liu, H.-L. and Roble, R. G.: A study of a self-generated stratospheric sudden warming and its mesosphericlower thermospheric impacts using the coupled TIMEGCM/CCM3, J. Geophys. Res.-Atmos., 107, 4695, https://doi.org/10.1029/2001JD001533, 4695, 2002.

Liu, H.-L., Wang, W., Richmond, A. D., and Roble, R. G.: Ionospheric variability due to planetary waves and tides for solar minimum conditions, J. Geophys. Res.-Space, 115, A00G01, https://doi.org/10.1029/2009JA015188, 2010.

Liu, H.-L., Bardeen, C. G., Foster, B. T., Lauritzen, P., Liu, J., Lu, G., Marsh, D. R., Maute, A., McInerney, J. M., Pedatella, N. M., Qian, L., Richmond, A. D., Roble, R. G., Solomon, S. C., Vitt, F. 
M., and Wang, W.: Development and Validation of the Whole Atmosphere Community Climate Model With Thermosphere and Ionosphere Extension (WACCM-X 2.0), J. Adv. Model. Earth Sy., 10, 381-402, 2018.

Malin, S. and Chapman, S.: The determination of lunar daily geophysical variations by the Chapman-Miller method, Geophys. J. Int., 19, 15-35, 1970.

Manoj, C., Lühr, H., Maus, S., and Nagarajan, N.: Evidence for short spatial correlation lengths of the noontime equatorial electrojet inferred from a comparison of satellite and ground magnetic data, J. Geophys. Res.-Space, 111, A11312, https://doi.org/10.1029/2006JA011855, 2006.

Matsuno, T.: A dynamical model of the stratospheric sudden warming, J. Atmos. Sci., 28, 1479-1494, 1971.

Maute, A., Hagan, M., Richmond, A., and Roble, R.: TIME-GCM study of the ionospheric equatorial vertical drift changes during the 2006 stratospheric sudden warming, J. Geophys. Res.-Space, 119, 1287-1305, 2014.

Maute, A., Hagan, M. E., Yudin, V., Liu, H.-L., and Yizengaw, E.: Causes of the longitudinal differences in the equatorial vertical $E \times B$ drift during the $2013 \mathrm{SSW}$ period as simulated by the TIME-GCM, J. Geophys. Res.-Space, 120, 5117-5136, https://doi.org/10.1002/2015JA021126, 2015.

Maute, A., Fejer, B., Forbes, J., Zhang, X., and Yudin, V.: Equatorial vertical drift modulation by the lunar and solar semidiurnal tides during the 2013 sudden stratospheric warming, J. Geophys. Res.Space, 121, 1658-1668, https://doi.org/10.1002/2015JA022056, 2016.

Menvielle, M. and Berthelier, A.: The K-derived planetary indices: Description and availability, Rev. Geophys., 29, 415-432, https://doi.org/10.1029/91RG00994, 1991.

McLandress, C.: The seasonal variation of the propagating diurnal tide in the mesosphere and lower thermosphere. Part II: The role of tidal heating and zonal mean winds, J. Atmos. Sci., 59, $907-$ 922, 2002

Montgomery, D. C., Peck, E. A., and Vining, G. G.: Introduction to linear regression analysis, vol. 821, John Wiley \& Sons, 2012.

Park, J., Lühr, H., Kunze, M., Fejer, B. G., and Min, K. W.: Effect of sudden stratospheric warming on lunar tidal modulation of the equatorial electrojet, J. Geophys. Res.-Space, 117, A03306, https://doi.org/10.1029/2011JA017351, 2012.

Pedatella, N., Liu, H.-L., and Richmond, A.: Atmospheric semidiurnal lunar tide climatology simulated by the whole atmosphere community climate model, J. Geophys. Res.-Space, 117, A06327, https://doi.org/10.1029/2012JA017792, 2012.

Pedatella, N., Chau, J., Schmidt, H., Goncharenko, L., Stolle, C., Hocke, K., Harvey, V., Funke, B., and Siddiqui, T.: How Sudden Stratospheric Warming Affects the Whole Atmosphere, Eos, https://doi.org/10.1029/2018EO092441, 2018a.

Pedatella, N., Liu, H.-L., Marsh, D., Raeder, K., Anderson, J., Chau, J., Goncharenko, L., and Siddiqui, T.: Analysis and Hindcast Experiments of the 2009 Sudden Stratospheric Warming in WACCMX+ DART, J. Geophys. Res.-Space, 123, 3131-3153, $2018 \mathrm{~b}$.

Pedatella, N. M. and Forbes, J. M.: Evidence for stratosphere sudden warming-ionosphere coupling due to vertically propagating tides, Geophys. Res. Lett., 37, L11104, https://doi.org/10.1029/2010GL043560, 2010.

Pedatella, N. M. and Liu, H.: The influence of atmospheric tide and planetary wave variability during sudden stratosphere warm- ings on the low latitude ionosphere, J. Geophys. Res.-Space, 118, 5333-5347, https://doi.org/10.1002/jgra.50492, 2013.

Pedatella, N. M., Fuller-Rowell, T., Wang, H., Jin, H., Miyoshi, Y., Fujiwara, H., Shinagawa, H., Liu, H.-L., Sassi, F., Schmidt, H., Matthias, V., and Goncharenko, L.: The neutral dynamics during the 2009 sudden stratosphere warming simulated by different whole atmosphere models, J. Geophys. Res.-Space, 119, 13061324, https://doi.org/10.1002/2013JA019421, 2014.

Rastogi, R. and Klobuchar, J.: Ionospheric electron content within the equatorial F2 layer anomaly belt, J. Geophys. Res.-Space, 95, 19045-19052, 1990.

Reay, S. J., Clarke, E., Dawson, E., and Macmillan, S.: Operations of the World Data Centre for Geomagnetism, Edinburgh, Data Sci. J., 12, WDS47-WDS51, https://doi.org/10.2481/dsj.WDS005, 2013.

Sassi, F., Liu, H.-L., Ma, J., and Garcia, R. R.: The lower thermosphere during the northern hemisphere winter of 2009: A modeling study using high-altitude data assimilation products in WACCM-X, J. Geophys. Res.-Atmos., 118, 8954-8968, 2013.

Sathishkumar, S. and Sridharan, S.: Lunar and solar tidal variabilities in mesospheric winds and EEJ strength over Tirunelveli $\left(8.7^{\circ} \mathrm{N}, 77.8^{\circ} \mathrm{E}\right)$ during the 2009 major stratospheric warming, J. Geophys. Res.-Space, 118, 533-541, https://doi.org/10.1029/2012JA018236, 2013.

Siddiqui, T. A., Lühr, H., Stolle, C., and Park, J.: Relation between stratospheric sudden warming and the lunar effect on the equatorial electrojet based on Huancayo recordings, Ann. Geophys., 33, 235-243, https://doi.org/10.5194/angeo-33-235-2015, 2015a.

Siddiqui, T. A., Stolle, C., Lühr, H., and Matzka, J.: On the relationship between weakening of the northern polar vortex and the lunar tidal amplification in the equatorial electrojet, J. Geophys. Res.-Space, 120, 10006-10019, https://doi.org/10.1002/2015JA021683, 2015b.

Siddiqui, T. A., Stolle, C., and Lühr, H.: Longitude-dependent lunar tidal modulation of the equatorial electrojet during stratospheric sudden warmings, J. Geophys. Res.-Space, 122, 37603776, 2017.

Sridharan, S., Sathishkumar, S., and Gurubaran, S.: Variabilities of mesospheric tides during sudden stratospheric warming events of 2006 and 2009 and their relationship with ozone and water vapour, J. Atmos. Sol.-Terr. Phys. 78, 108-115, 2012.

Stening, R.: An assessment of the contributions of various tidal winds to the Sq current system, Planet. Space Sci., 17, 889-908, 1969.

Stening, R. J.: A calculation of ionospheric currents due to semidiurnal antisymmetric tides, J. Geophys. Res.-Space, 94, 15251531, 1989.

Stening, R. J., Meek, C. E., and Manson, A. H.: Upper atmosphere wind systems during reverse equatorial electrojet events, Geophys. Res. Lett., 23, 3243-3246, https://doi.org/10.1029/96GL02611, 1996.

Tapping, K.: The $10.7 \mathrm{~cm}$ solar radio flux (F10.7), Space Weather, 11, 394-406, 2013.

Tarpley, J. D.: The ionospheric wind dynamo-II. Solar tides, Planet. Space Sci., 18, 1091-1103, https://doi.org/10.1016/00320633(70)90110-8, 1970.

Taylor, J.: Introduction to error analysis, the study of uncertainties in physical measurements, University Science Books, 1997. 
Vineeth, C., Kumar Pant, T., and Sridharan, R.: Equatorial counter electrojets and polar stratospheric sudden warmings - a classical example of high latitude-low latitude coupling?, Annal. Geophys., 27, 3147-3153, https://doi.org/10.5194/angeo-27-31472009, 2009.

Wang, H., Fuller-Rowell, T., Akmaev, R., Hu, M., Kleist, D., and Iredell, M.: First simulations with a whole atmosphere data assimilation and forecast system: The January 2009 major sudden stratospheric warming, J. Geophys. Res.-Space, 116, A12321, https://doi.org/10.1029/2011JA017081, 2011.

Yadav, S., Pant, T. K., Choudhary, R., Vineeth, C., Sunda, S., Kumar, K., Shreedevi, P., and Mukherjee, S.: Impact of Sudden Stratospheric Warming of 2009 on the Equatorial and LowLatitude Ionosphere of the Indian Longitudes: A Case Study, J. Geophys. Res.-Space Phys., 122, 10486-10501, 2017.

Yamazaki, Y.: Large lunar tidal effects in the equatorial electrojet during northern winter and its relation to stratospheric sudden warming events, J. Geophys. Res.-Space, 118, 7268-7271, https://doi.org/10.1002/2013JA019215, 2013.
Yamazaki, Y.: Solar and lunar ionospheric electrodynamic effects during stratospheric sudden warmings, J. Atmos. Sol.-Terr. Phys., 119, 138-146, 2014.

Yamazaki, Y., Richmond, A., and Yumoto, K.: Stratospheric warmings and the geomagnetic lunar tide: 1958-2007, J. Geophys. Res.-Space, 117, A04301, https://doi.org/10.1029/2012JA017514, 2012.

Yamazaki, Y., Richmond, A., Maute, A., Liu, H.-L., Pedatella, N., and Sassi, F.: On the day-to-day variation of the equatorial electrojet during quiet periods, J. Geophys. Res.-Space, 119, 69666980, 2014.

Zhang, X., Forbes, J. M., and Hagan, M. E.: Longitudinal variation of tides in the MLT region: 2. Relative effects of solar radiative and latent heating, J. Geophys. Res.-Space, 115, A06317, https://doi.org/10.1029/2009JA014898, 2010.

Zhou, Y.-L., Lühr, H., Xu, H.-W., and Alken, P.: Comprehensive analysis of the counter equatorial electrojet: Average properties as deduced from CHAMP observations, J. Geophys. Res.-Space, 123, 5159-5181, https://doi.org/10.1029/2018JA025526, 2018. 